HNF-2906

Revision 1

\title{
Nested Fixed-Depth Fluidic Sampler and At-Tank Analysis System Deployment Strategy and Plan
}

Prepared for the U.S. Department of Energy

Assistant Secretary for Environmental Management

\section{CH2MHILL}

Hanford Group, Inc.

Richland, Washington

Contractor for the U.S. Department of Energy

Office of River Protection under Contract DE-AC06-99RL14047

Approved for Public Release; Further Dissemination Unlimited 
HNF-2906

Revision 1

\section{Nested Fixed-Depth Fluidic Sampler and At-Tank Analysis System Deployment Strategy and Plan}

Prepared by:

F. R. Reich

COGEMA Engineering Corporation

K. A. Gasper

J. N. Appel

$\mathrm{CH} 2 \mathrm{M}$ Hill Hanford Group, Inc.

Date Published

February 2000

Prepared for the U.S. Department of Energy

Assistant Secretary for Environmental Management

\section{CH2MHILL \\ Hanford Group, Inc.}

P. O. Box 1500

Richland, Washington

Contractor for the U.S. Department of Energy

Office of River Protection under Contract DE-AC06-99RL14047

Approved for Public Release; Further Dissemination Unlimited 


\section{INFORMATION CLEARANCE FORM}

\begin{tabular}{|c|c|}
\hline \multicolumn{2}{|c|}{ A. Information Category } \\
\hline$\square$ Abetract & Joumal Artich \\
\hline$\square$ summary & intemat \\
\hline$\square$ Vivual Ad & Sotwmare \\
\hline$\square$ Full Papar & Roport \\
\hline$\square$ other & \\
\hline
\end{tabular}
B. Document Number HNF-2906, Rev. 1
C. This
Nested Fixed-Depth Fluidic Sampler and At-Task Analysis system Deployment strategy and Plan
D. Internat Addreas $N / A$

E. Requined Information

1. Is document potentillyy cligeined? ONo OYes (MANDATORY) 8.m. Boare

if Yes ADC Signature Required

2. Intemal Roview Required? if Yes, Document Slonatures Below ONo Oras clasedfiad

Couneal

Program $\mathrm{R} m \cdot \mathrm{B}_{\mathrm{s}} \mathrm{k}=$

3. References in the Intormation are Applied Techmoloty Export Controlied information
ONo OYes

\section{1}

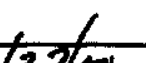

\section{4}
a. Now or Novel (Palontable) subject Matter $\mathrm{O}$ No Ores
Iros", Dhoboure No.:

b. Information Recalved in Confidence, Such as Propritary and/or Inventons?

ONo OYes If'Yos", Alix Appropriate Legenda/Notices.
c. Copyrights? ONo OYos If "Yos", Attach Pormisaion.
d. Tredemerke? ONo OYes "Yes", Identily in Document.

5. le Information requiring submisclon to OSTI? $O$ No $O$ Yes

II Yos UC- 2020 and $B \& R-$ EW 3120074

6. Rolease Leven $O$ Public $O$ Limited

7. Chargo Codo HMLM0331 10₹ 206/ES 10

\section{F. Complete for Joumal Articie}

1. Thte of Joumal $N / A$

\section{G. Complete for Presentation}

1. Tith for Conierence or Meeting $N / A$

2. Group Sponaring

3. Date of Conterence

5. Will Information be Published in Proceedinge? ONo OYes

4. Clty/State

H. Authorifequastor

F. R. Reich (Print and Sign)

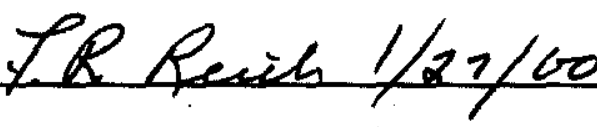

6. Will Material be Handed Out? $\bigcirc$ No $\bigcirc$ Yes

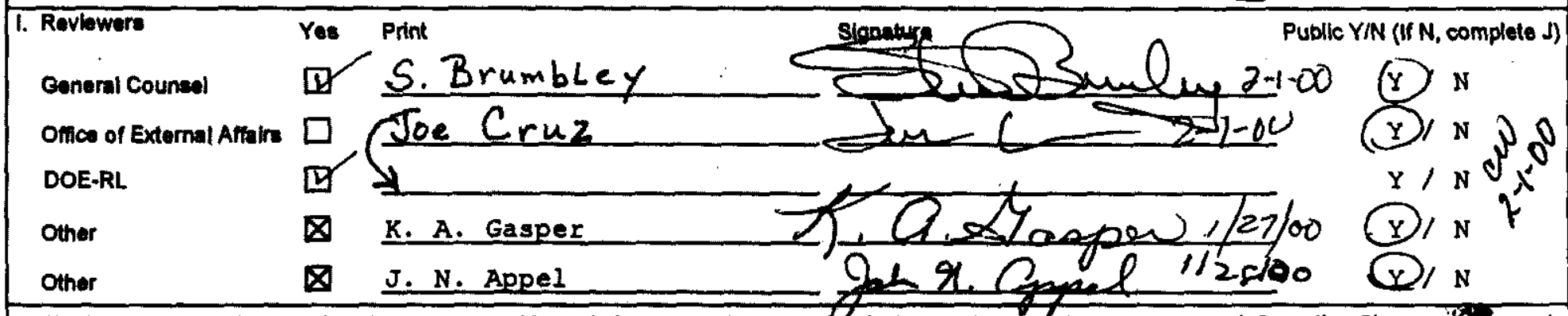

J. If Information Includes Sencitive Information and ls not to be released to the Pubfic indicate category below.

$\square$ Applied Technology $\square$ Protected CRADA

$\square$ pereonavituate $\square$ Export Controlled

$\square$ Propriotary $\square$ Procurement-Seneitive

$\square$ Busineas-senalive $\square$ Patentable

$\square$ Predeclajonal $\square$ other (Specify)

$\square$ UCNI

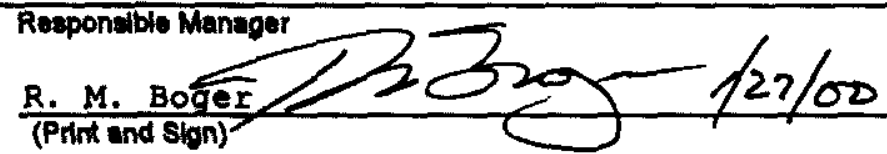




\section{RELEASE AUTHORIZATION}

\begin{tabular}{ll}
$\begin{array}{l}\text { Document } \\
\text { Number: }\end{array}$ & HNF-2906, Rev. 1 \\
\hline $\begin{array}{l}\text { Document } \\
\text { Title: }\end{array}$ & $\begin{array}{l}\text { Nested Fixed-Depth Fluldic Sampler and At-Tank } \\
\text { Analysis System Deployment strategy and Plan }\end{array}$
\end{tabular}

This document, reviewed in accondance with DOE Order 1430.1D, "Scientilc and Technical Information Management," and DOE G 1430.1D-1,

"Guide to the Management of Sclentific and Technical information," does not contain classified or sensitive unclaselfied information and 18:

\section{APPROVED FOR PUBLIC RELEASE}

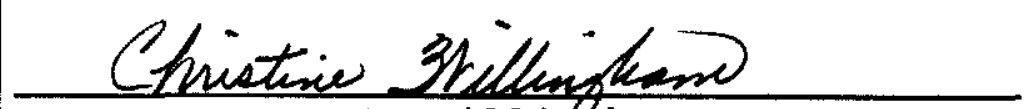

C. Willingham
$2 / 1 / 2000$

Date

Lockheed Martin Services, Inc.

Document Control / Information Clearance

Reviewed for Applled Technology, Buelnese Sensitve, Cheslifed, Copyrighted Export Controlled, Patent, Pereonal/Private, Propristary, Protected CRADA, Trademerk, Unctaselited Controfted Nucter intormation.

LEGAL DISCLAIMER. This report we prepared as an eccount of work eponeored by en acanoy of the United States

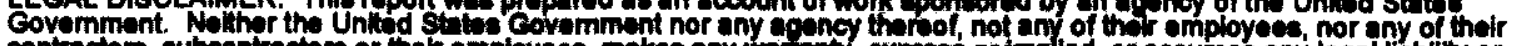

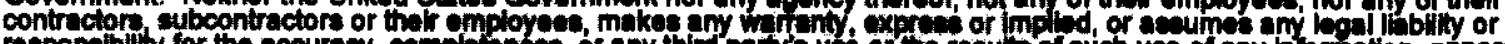

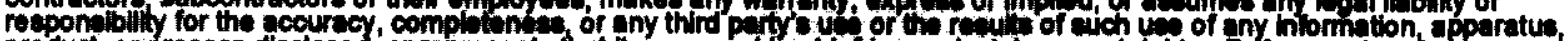

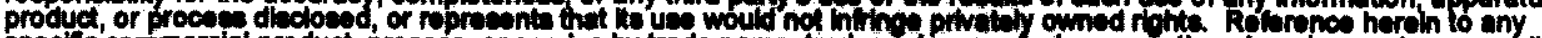

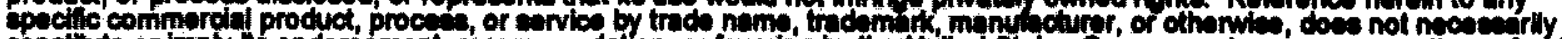

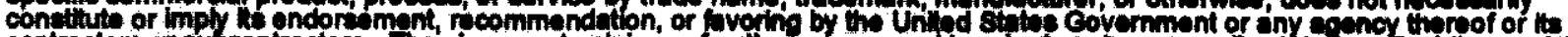

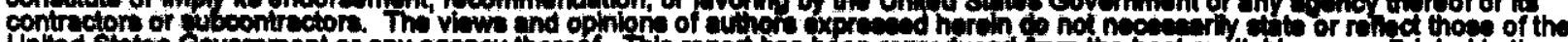

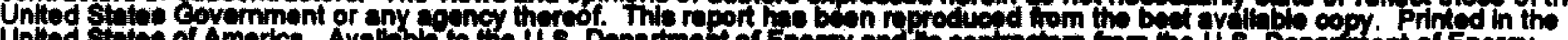

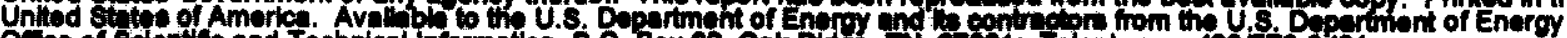

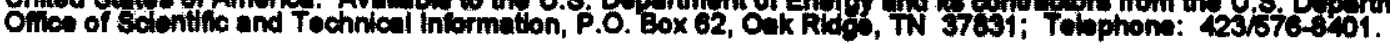

Available to the public from the U.S. Deparment of Commerce National Technical Information Service, 5285 Port Royal Road, Springfield, VA 22161; Telephone: 705/487-4650. 


\section{EXECUTIVE SUMMARY}

Under the Hanford Site River Protection Project (RPP) privatization strategy, the U.S. Department of Energy (DOE) Office of River Protection (ORP) requires the CH2M Hill Hanford Group, Inc. (CHG) to supply tank waste to the privatization contractor, BNFL Inc. (BNFL), for separation and/or treatment and immobilization (vitrification). Three low-activity waste (LAW) specification envelopes represent the range of liquid waste types in the large, Hanford Site underground waste storage tanks. The CHG also is expected to supply high-level waste (HLW) separation and/or treatment and disposal. The HLW envelope is an aqueous slurry of insoluble suspended solids (sludge). The Phase 1 demonstration will extend over 24 years (1996 through 2019) and will be used to resolve technical uncertainties. About one-tenth of the total Hanford Site tank waste, by mass, will be processed during this period.

This document provides a strategy and top-level implementation plan for demonstrating and deploying an alternative sampling technology. The alternative technology is an improvement to the current grab sampling and core sampling approaches that are planned to be used to support the RPP privatization contract. This work also includes adding the capability for some at-tank analysis to enhance the potential of this new technology to meet CHG needs. The first application is to LAW and HLW feed staging for privatization; the next is to support cross-site waste transfer from 200 West Area tanks.

In the first quarter of fiscal year (FY) 1998, the RPP (then known as the Tank Waste Remediation System or TWRS) Retrieval and Disposal Mission readiness-to-proceed activities identified the primary uncertainties and risks that must be managed to successfully support the RPP Privatization Phase 1 activities. Four of the critical risks could be mitigated, at least partially, by using an improved alternative to grab sampling. In addition, eight additional risks that are associated with the Waste Feed Delivery project involved the sampling activities.

Technical basis reviews (TBR) for more than 25 logic elements were evaluated and found to be relevant to risk mitigation using an improved alternative to grab sampling.

This revision of the document describes the risks currently identified with the FY 2000 multiyear program plan. Generally, the benefits are associated with reducing the amount of sampling that needs to be done before analysis can confirm that the tank contents are ready for transfer to the BNFL RPP Waste Treatment Plant (WTP) and ensuring timely delivery of the waste feed to avoid RPP payments associated with idle WTP facility costs. These payments are currently estimated to be $\$ 2.5$ million per day. Reducing the risk associated with radiation exposure to the sampling crews is another area where the new sampling approach benefits the Hanford Site.

The deployment strategy focuses on developing the sampling concept for taking representative samples at various depths in a feed staging tank with the aid of process control data derived from waste property measurements taken by an at-tank analysis system. The process control data would be used to ensure that the waste samples are ready to be taken. A portion of the wastesample would be made available to the privatization contractor and a portion would go to the Project Hanford Management Contract (PHMC) Team's 222-S Analytical Laboratory. 
Given the current baseline plan and schedule, the proposed strategy is to first demonstrate and deploy this new capability for sampling either LAW feed or HLW feed in a feed staging tank using a set of equipment most of which can be moved from tank to tank. The equipment would be moved to the tank much as it is in the process used with the current core sampler truck at the Hanford Site, although probably a crane-deployed skid or group of skids would be used instead of a truck. When sampling is completed for that campaign, some hardware would be left in the tank if there were some likelihood that in future years that tank might be used again for feed staging. If not, that in-tank equipment would be removed and disposed of. In either case, the equipment above the tank riser would be relocated to the next feed staging tank needing sampling.

The development strategy for the sampling system will use a power fluidic technology that has been successfully used for several years in England. It will be coupled with a mobile sampling concept using the extensive Hanford Site experience with the core sampling truck system. The power-fluidic-technology-based sampling system was chosen because it can be operated under adverse weather conditions, it can be adapted to sampling while the large mixer pumps are agitating the tank waste, and it will minimize the time required to obtain the large samples needed. This system application also will benefit from the deployment of the fixed-depth power fluidic sampler at the Savannah River Site for waste similar to that at the Hanford Site. The development strategy consists of cold testing the system concept with waste simulants at an existing test facility by AEA Technology Engineering Services, Inc. (AEAT), the developer of the technology. The system then will be cold tested at the Hanford Site under conditions closer to what it will experience in the actual operations. Hanford Site personnel will conduct these tests with support from AEAT personnel. Next, the system will be hot tested in an actual double shell tank in the Hanford Site tank farm.

The deployment plan represents an integrated project of DOE's Office of Science and Technology, EM-50 supporting the EM-30 baseline activity. EM-50, through its Tanks Focus Area, International Programs, and Robotics Cross Cut Program provided $\$ 700,000$ of support in FY 1998. During this time the EM-50 Accelerated Site Technology Deployment (ASTD) program, in cooperation with the High-Level Waste Management organization at the Savannah River Site, funded installation of a fixed-depth sampler system at the Savannah River Site. At the Hanford Site, the TWRS Waste Retrieval Project, through its technology support task, supported the initial planning of the sampler and analysis project. In FY 1999 the Tanks Focus Area, International grants, Robotics, Characterization, Monitoring, and Sensor Technology (CMST) and Hanford Site Waste Retrieval programs made available \$1.1 million. Only about $\$ 1.0$ million of that was expended because of delays in proceeding with the at-tank analysis portion of the project. In FY 2000 these organizations are expected to provide about $\$ 1.4$ million to support further testing of the power fluidic concept adapted for Resource Conservation and Recovery Act of 1976 (RCRA)-compliant sampling and for conceptual design and the subsequent outline design of the mobile sampling system, including the portion used for at-tank analysis. The objectives for FY 2001 are to complete the detailed design for the mobile sampling and at-tank analysis systems. EM-30-funded tasks will include planning, preliminary hazards assessments, and update to the component specifications. In FY 2002 the fabrication and vendor checkout of the modules and components for the mobile sampling system will be completed. EM-30-funded tasks will include planning, preparing the cold test facility, and revising the hazards assessment. In FY 2003 EM-30 funds will support the completion of acceptance testing 
of the mobile sampling system and at-tank analysis system. Operation and performance verification of the systems and a hot system readiness review will be completed. In FY 2004, hot deployment, hot demonstration, and testing will be completed. The planned support from EM-50 and EM-30 (RPP Baseline) is summarized in Table ES-1. Additional deployments in the 200 West Area cross-site transfer staging tanks are assumed to be funded by EM-30.

Table ES-1. Development and Deployment Costs for the Mobile Fluidic Sampler for Low-Activity Waste and High-Level Waste Feed Staging.

\begin{tabular}{|c|c|c|c|c|c|c|c|c|}
\hline now & $10 \% 8$ & 40 & 4003 & $86 \%$. & $4 \%$ & 3018 & 20004 & 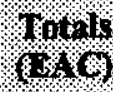 \\
\hline $\begin{array}{c}\text { EM-50 } \\
\text { (total } \$ \text { in } \\
\text { thousands) }\end{array}$ & $\$ 630$ & $\$ 1,033^{*}$ & $\$ 1,145$ & $\$ 1,320$ & $\$ 785$ & TBD & & $\$ 4,913$ \\
\hline $\begin{array}{l}\text { EM-30 } \\
\text { (total } \$ \text { in } \\
\text { thousands) }\end{array}$ & $\$ 50$ & $\$ 50$ & $\$ 260$ & $\$ 427$ & $\$ 735$ & $\$ 1,725$ & $\$ 625$ & $\$ 3,872$ \\
\hline $\begin{array}{l}\text { Project } \\
\text { (total \$ in } \\
\text { thousands) }\end{array}$ & $\$ 680$ & $\$ 1,083$ & $\$ 1,405$ & $\$ 1,747$ & $\$ 1,520$ & $\$ 1,725$ & $\$ 625$ & $\$ 8,785$ \\
\hline
\end{tabular}

*Includes a $\$ 70,000$ carryover from fiscal year 1998; and a $\$ 38,000$ carryover from fiscal year 1999.

$\mathrm{EAC}=$ estimate at completion.

$\mathrm{TBD}=$ to be determined.

All the digits have been retained in the cost estimates provided in Table ES- 1 to ensure traceability throughout the document and traceability to supporting documentation. These numbers are only preliminary planning numbers and have an uncertainty of perhaps \pm 25 percent or more.

The project team includes the principal investigator and the technical leadership provided by the RPP Characterization Engineering organization, program support by the RPP Process Waste Support organization, AEAT as the source of the power fluidic technology, and Pacific Northwest National Laboratory support both directly and through the Robotics program. In FY 1999 the EM-50 CMST Cross Cut Program began providing support and will involve other organizations with their expertise to participate in development and deployment. The National Energy Technology Laboratory (NETL) at Morgantown also began working with the project team in FY 1999 to select and place a contract with a private vendor for the at-tank analysis system. 


\section{HNF-2906 REV 1}

This page intentionally left blank. 


\section{CONTENTS}

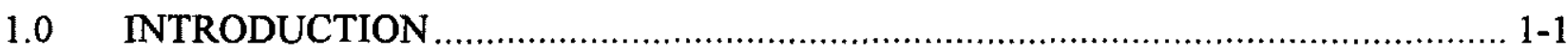

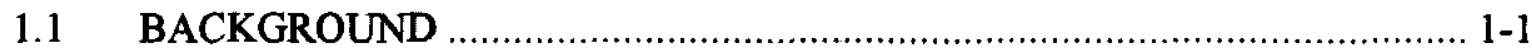

1.2 PURPOSE

1.2.1 Purpose of the Document............................................................. 1-3

1.2.2 Purpose of the Sampler and Analysis System ................................. 1-4

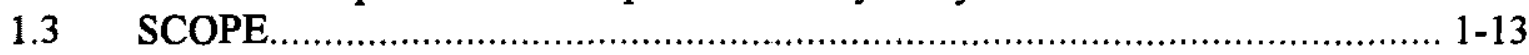

1.4 MISSION AND OBJECTIVES ........................................................ 1-13

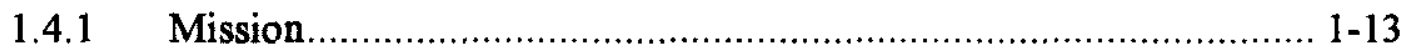

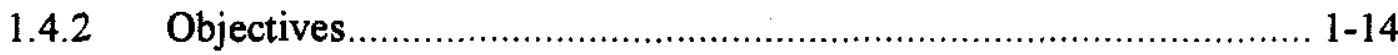

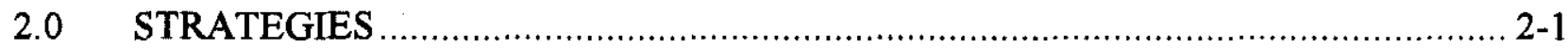

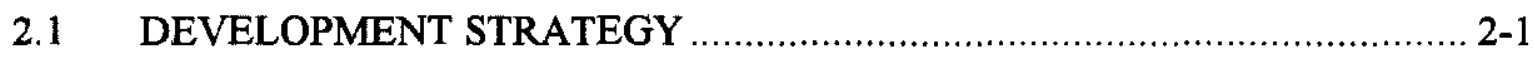

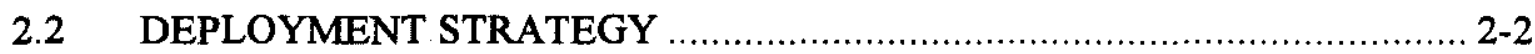

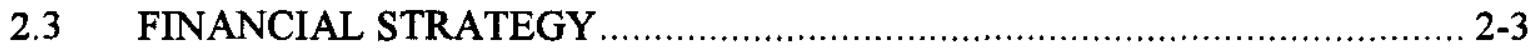

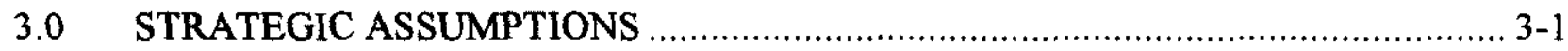

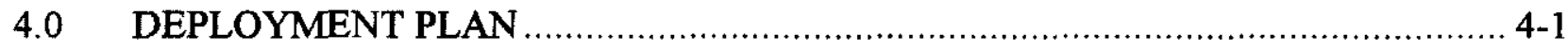

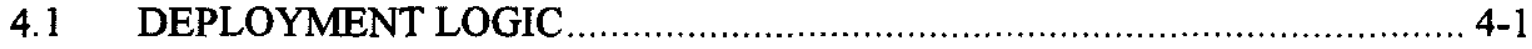

4.1.1 Sampler Development ................................................................ 4-1

4.1.2 System Specifications (Level 2 Component/ System

Specifications) ............................................................................... 4-3

4.1.3 Conceptual Design-Sampler..................................................... 4-3

4.1.4 Sampler Outline Design .......................................................... 4-4

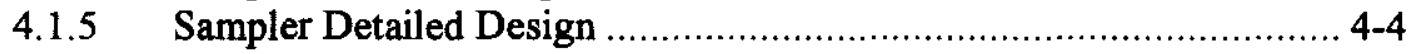

4.1.6 Decision-to-Proceed ..................................................................... 4-4

4.1.7 Sampler Fabrication ...................................................................... 4-4

4.1.8 Sampler Cold Test Preparation.................................................... 4-5

4.1.9 Sampler Acceptance Testing ..................................................... 4-5

4.1.10 Sampler Operational Testing...................................................... 4-5

4.1.11 Concept Development, Concept Validation Testing, and
Conceptual Design for the At-Tank Analysis System ….................... 4-5

4.1.12 Sensor System Evaluations ........................................................ 4-5

4.1.13 At-Tank Analysis Outline Design ……….................................... 4-5

4.1.14 At-Tank Analysis Detailed Design ................................................ 4-6

4.1.15 Review and Decision-to-Proceed ................................................ 4-6

4.1.16 At-Tank Analysis System Fabrication ......................................... 4-6

4.1.17 At-Tank Analysis System Acceptance Testing ……......................... 4-6

4.1.18 At-Tank Analysis System Operational Testing ................................. 4-6

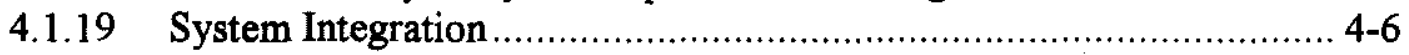

4.1.20 Integrated System Testing and Operator Training ............................ 4-7

4.1.21 Authorization Basis Update and Environmental Permitting................ 4-7

4.1.22 Hot Installation Readiness Review and System Preparation .............. 4-7 


\section{HNF-2906 REV 1}

4.1.23 Hot Installation and Testing .........................................................

4.2 PLANNING ASSUMPTIONS ……......................................................

4.3 DEVELOPMENT AND DEPLOYMENT SCHEDULE ........................... 4-8

4.4 DEVELOPMENT AND DEPLOYMENT COST .............................. 4-11

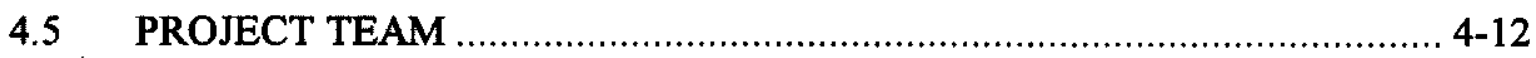

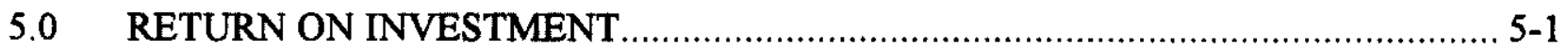

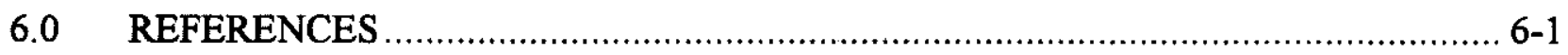

\section{APPENDICES}

A COMPARISON OF OPERATIONAL LOGIC AND SCHEDULES FOR

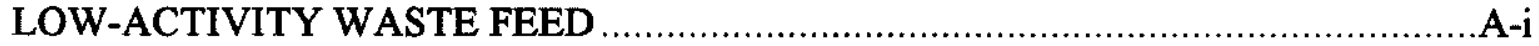

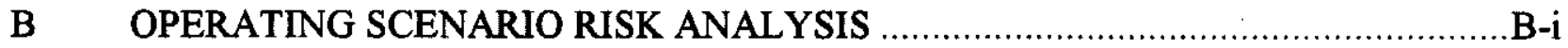

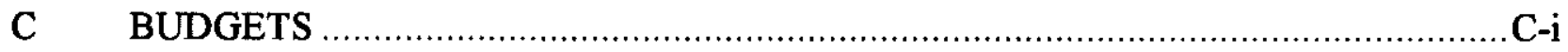

D SUMMARY OF ALTERNATIVES EVALUATION ............................................... 
HNF-2906 REV 1

LIST OF FIGURES

Figure 1-1. Mobile, Variable-Depth Sampling System Deployed in a Hanford Site Double-Shell Tank.

Figure 1-2. Mobile, Variable Depth Sampling System Showing Its Major Components and Interfaces for the RCRA Compatible Bottle-Filling Station and At-Tank Analysis System.

Figure 1-3. Bottle-Filling Station Designed to Meet RCRA Criteria for Volatile and Semivolatile Organic Materials.

Figure 4-1. Deployment Logic for the Mobile, Variable Depth Sampler System.

Figure 4-2. Sampler and At-Tank Analysis System Development and Deployment Schedule. (2 Sheets). 


\section{TERMS}

AEAT

AGA

ALARÁ

ASTD

BNFL

CHG

CMST

DOE

FY

HLW

ICD

IPT

LAW

MYWP

NETL

NEPA

ORP

PHMC

RAM

RCRA

RFD

ROI

RPP

STCG

TBR

TFA

TIM

Tri-Party Agreement

TWRS

WFD

WTD

WTP
AEA Technology Engineering Services, Inc.

alternatives generation and analysis

as low as reasonably achievable

Accelerated Site Technology Deployment

BNFL Inc.

CH2M Hill Hanford Group, Inc.

Characterization, Monitoring and Sensor Technology

U.S. Department of Energy

fiscal year

high-level waste

Interface Control Document

Integrated Products/Process Team

low-activity waste

multi-year work plan

National Energy Technology Laboratory

National Environmental Policy Act of 1969

Office of River Protection

Project Hanford Management Contract

reliability, availability, and maintainability

Resource Conservation and Recovery Act of 1976

reverse flow diverter

return on investment

River Protection Project

Site Technology Coordinating group

Technical Basis Review

Tanks Focus Area

Technical Integration Manager

Hanford Federal Facility Agreement and Consent Order

Tank Waste Remediation System

Waste Feed Delivery

waste transfer day

Waste Treatment Plant 
HNF-2906 REV 1

\section{NESTED FLXED-DEPTH FLUIDIC SAMPLER AND AT-TANK ANALYSIS SYSTEM DEPLOYMENT STRATEGY AND PLAN}

\subsection{INTRODUCTION}

\subsection{BACKGROUND}

Under the Hanford Site River Protection Project (RPP), then known as the Tank Waste Remediation System (TWRS), a privatization strategy was embodied in a contract signed with BNFL Inc.(BNFL) in September 1996 for the U.S. Department of Energy (DOE) to purchase services from a contractor-owned, contractor-operated facility under a fixed-price contract. The $\mathrm{CH} 2 \mathrm{M}$ Hill Group, Inc. (CHG)/Project Hanford Management Contract (PHMC) Team will supply tank waste to BNFL for separation and/or treatment and immobilization (vitrification). Three low-activity waste (LAW) envelopes are identified for Phase 1 of the contracts. These represent the range of liquid waste types in the large underground waste storage tanks on the Hanford Site: double-shell slurry/double-shell slurry feed (Envelope A); aging waste, also known as neutralized current acid waste (Envelope B); and organic complexant-containing complexed concentrate (Envelope $C$ ). Waste of all these types will be delivered as dilute slurry solutions with a maximum of 2 percent by weight solids. The contract also includes high-level waste (HLW) treatment services; one HLW envelope will be provided. This envelope, Envelope D, is an aqueous slurry of insoluble suspended solids (sludge). The demonstration period will extend over more than 10 years. Waste will be processed during this period, resulting in 6 to 13 percent of the total Hanford Site tank waste being treated.

In fiscal year (FY) 1996, DOE's Office of Science and Technology, EM-50, funded AEA Technology Engineering Services, Inc. (AEAT), to install and operate a fluidics pump and sampler demonstration system in Charlotte, North Carolina. In October 1996, the pump and sampler operation was demonstrated to personnel from the DOE, the Tanks Focus Area (TFA), and the representatives from DOE's Oak Ridge, Savannah River, Idaho, and Hanford sites. During the period immediately preceding this demonstration, AEAT also completed a conceptual design report that included a fluidics sampler for Savannah River Site tank 49, one of the in-tank precipitation process tanks.

In September 1996 the documentation of the alternatives generation and analysis (AGA) was completed at the Hanford Site to address the question: "What is the design basis for the facilities required to stage LAW feed to the Phase I Privatization Contractors?" This AGA included the evaluation of three alternatives for sampling waste feed: grab sampling, core sampling, and the Isolok1-type sampling system. The Isolok-type system used the conceptual design that was completed for the grout disposal program to obtain representative samples of the feed batches in the staging tanks (Claghorn 1997). This evaluation is summarized briefly in Appendix D.

1 Isolok is a trademark of Bristol Engineering Company. 


\section{HNF-2906 REV 1}

From October through November of 1996, the decision panel considering the AGA looked at the AEAT fluidics sampler concept being pursued at the Savannah River Site. At that time, the panel agreed to proceed with the grab sampler as the baseline approach to ensure that the baseline schedule was met. The panel also agreed that DOE should seek funding through the Site Technology Coordinating Group (STCG) Tank Subgroup to pursue the AEAT approach at the Hanford Site as an improved alternative to the baseline. Assuming that the AEAT concept works as foreseen, it will be phased into the baseline as soon as practical. The proposal was written, approved by the STCG, and has resulted in the formation of the current integrated project. In FY 1998 and FY 1999, the EM-50 International Programs/International Grants program provided funding to AEAT to develop a nested, fixed-depth sampler system (initially called "Variable Depth Fluidics Sampling and Analysis") for demonstration at the end of FY 1998 and funding for further testing in FY 1999 in AEAT facilities in Charlotte, North Carolina, using nonradioactive tank waste simulants. The TFA provided funding in FY 1998 and FY 1999 to the CHG/PHMC Team to lead the development and deployment of the tank sampler and at-tank analysis system. The Robotics Cross Cut Program provided the Pacific Northwest National Laboratory with funding in FY 1998 and FY 1999 to support the at-tank analysis portion of this system (Bailey 1998). In FY 1998, the Accelerated Site Technology Deployment (ASTD) program, in cooperation with the High-Level Waste Management organization at the Savannah River Site, funded a technology deployment initiative to install a fixed-depth sampler system in tank 49 to support the Savannah River Site's in-tank precipitation efforts (Bailey 1998). At the Hanford Site, the TWRS Waste Retrieval Project, through its technology support task, supported the planning and project management of the sampler and analysis project in both FY 1998 and FY 1999.

AEAT initially considered five fluidics sampler concepts as being feasible for acquiring representative samples from different waste depths in the TWRS feed staging tanks. The five concepts were telescoping flexible hose, hoisting slotted pipe, and nested fixed-depth sampling. A Hanford Site team, including technical staff from the PHMC Team and the Pacific Northwest National Laboratory, evaluated the alternatives and selected the nested fixed-depth concept based on a preliminary set of functions and requirements. These 32 criteria included safety, operability, maintainability, operational life, decontamination, environmental, and sample shipping in addition to the data quality objectives-type items.

In FY 1998 AEAT completed the conceptual design for and demonstrated a nested, fixed-depth concept using simulants representative of waste in the Hanford Site tanks. In FY 1999 further validation testing was conducted at AEAT facilities to ensure that a full-height (17 $\mathrm{m}$ [57-ft]) tank could be representatively sampled, no inadvertent release of waste would occur if the sample bottle were not in place, and that the sampler, if it became plugged, could be unplugged. Project requirements were modified by the U.S. Department of Energy, Office of River Protection (ORP) to include criteria that required Resource Conservation and Recovery Act of 1976 (RCRA)-compliant sampling for volatile organics. The need for a different sample-bottlefilling approach emerged from these test results and the requirements modification. An AGA (trade study) was completed and several promising concepts were identified for testing that is planned to be completed in FY 2000. 


\section{HNF-2906 REV 1}

As ORP and the CHG/PHMC Team evaluated risk-mitigating approaches to ensure timely waste feed delivery (WFD) to support privatization, the concept of staging feed from two LAW tanks and perhaps two HLW tanks was modified. The new strategy will be to provide waste staging and feed delivery from tanks in at least four different tank farms: the AN, AZ, AY, and AP tank farms. This necessitated revisiting the existing strategy where nested, fixed-depth samplers would be permanently installed in a few feed tanks (e.g., tanks 241-AP-102 and 241-AP-104 for LAW feed staging) for the duration of the waste treatment and immobilization activities. What emerged as the concept to be pursued in FY 2000 is a mobile, variable-depth sampling concept using features and lessons learned from the present baseline core sampling trucks along with the power fluidic technology and testing associated with this representative sampling project.

\subsection{PURPOSE}

\subsubsection{Purpose of the Document}

This document has two primary purposes. The first is to provide the strategy for the following activities:

1. The demonstration and deployment of power fluidic sampling technology as an improved alternative to the current grab-sampling approach for LAW feed staging and the current grab sampling and core sampling for HLW feed staging to support the RPP

2. Adding to this sampling technology the capability to make at-tank waste measurements that will provide additional support (particularly process control data) to the LAW and HLW feed staging

3. Adding the capability for using this sampling and, perhaps, at-tank analysis technology to feed source tanks to the 200 West Area SY tank farm and the related cross-site transfer system.

The second purpose is to provide a top-level implementation plan for carrying out the strategy pertaining to LAW and HLW feed staging tanks (Items 1 and 2). This plan will include an approach for leveraging the EM-50 Technology Development Program's support for these technology development opportunities to achieve goals common to EM-50 and the RPP. This document will serve as a basis for implementing the revised RPP FY 2000 MYWP and detailed planning of support for the Representative Sampler Project (i.e., preparation of the revised engineering task plan, HNF-2056).

This top-level implementation plan, as well as the more detailed engineering task plan, will focus on developing and deploying the sampling and at-tank analysis technology on the LAW and HLW feed staging tanks. Only a brief discussion is included on the use of these systems in the 200 West Area SY tank farm and the related cross-site transfer system (Item 3). 


\section{HNF-2906 REV 1}

\subsubsection{Purpose of the Sampler and Analysis System}

1.2.2.1 Existing Condition. Grab sampling is the baseline waste sampling approach for LAW feed sampling and one of the two approaches for HLW feed sampling. Core sampling is the other. This sampling method is a manual operation and is performed by lowering a stoppered bottle by a cable into the feed staging tank. A glove bag is set up over the riser to provide contamination control during sampling and packaging of the samples. This allows sampling without the need for a containment tent. The sample bottle is held in a weighted fixture that may have a pointed end to help penetrate the tank waste. The cable is marked to allow the operators to determine the depth of the sample within the tank waste. When the bottle reaches the desired depth, the cable is jerked, which opens the bottle and allows it to be filled with waste. The filled sample bottle is then retrieved along with the cable. The bottle is open, which may allow the sample to be cross-contaminated with waste from above the sampling depth as the bottle is retrieved. After the sample bottle is retrieved into the glovebag, the sample bottle closure is placed on the bottle, which seals it. The outside of the sample bottle is flushed with water and wiped to remove surface contamination. The bottle is then bagged and put into a pig for shipment to the 222-S Laboratory. If the waste is highly radioactive, an operator may use lead-lined gloves and temporary shielding to reduce radiation dose levels.

The advantages of grab sampling are that it is a relatively simple operation, requires no complex construction, and should have no impact on project schedule or other milestones. All performance requirements are currently established and grab sampling is reliable and easy to complete. Grab sampling has a number of disadvantages, including the following.

- A moderate, recurring sample cost is incurred.

- A potential exists for the sampling to not be repeatable at a given depth.

- The process has potentially high personnel exposure and a high potential for contamination (as low as reasonably achievable [ALARA] considerations)

- The process can take from several hours to a couple of days to get samples from all depths that will be required in a feed tank.

- This is the sampling process that is the most susceptible to being delayed by bad weather conditions. It is frequently delayed by wind, precipitation, etc.

- Ensuring representative samples during tank waste settling is impossible.

- Sampling cannot be completed when the mixer pumps are operating.

- Using this method, acquiring the multiliter sample quantities now sought is difficult.

- The process is not readily adaptable to increases in baseline throughput rate of feed staging (e.g., by a factor of 2 ).

1.2.2.2 New Condition Desired. A new sampling approach is proposed that uses a mobile, variable-depth sampling system to obtain samples from a waste tank. The sampling system 
provides LAW and HLW samples that meet the RCRA-specified criteria for materials containing volatile and semivolatile materials as required by the RPP privatization contract. An at-tank analysis system could be interfaced with the waste stream from the sampler to provide on-line, real-time waste physical and chemical property data from which the homogeneity of the waste batch could be assessed.

Figure 1-1 shows the mobile, variable-depth sampling system deployed in a Hanford Site doubleshell tank. The sampling system is self-contained and mounted on a skid that would be deployed with a crane (this skid also could be mounted on the back of a truck). This means that a clear path to a tank riser, as currently is required by the core truck systems, is not necessary. The electrical, compressed air, and water utilities needed to operate this sampling system also would be contained on the skid.

Figure 1-1. Mobile, Variable-Depth Sampling System Deployed in a Hanford Site Double-Shell Tank.

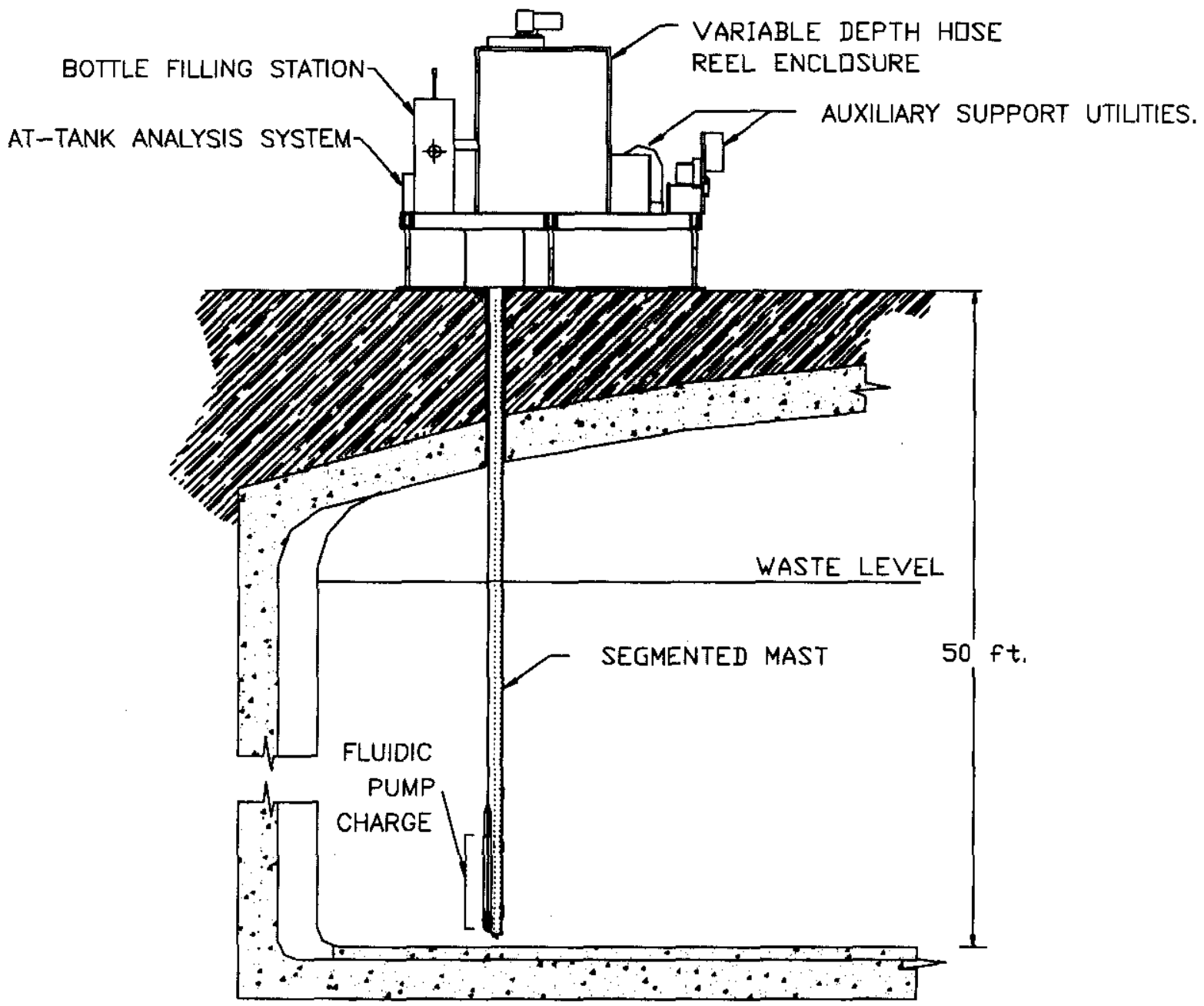


The sampling would be done by a power fluidic pump (charge vessel and reverse flow diverter [RFD]) that has no moving components in contact with the tank waste (the RFD is the inlet for the sampling system). The sampling system has a segmented mast that is deployed through a tank riser. The sampling system is designed as a stand-alone system. However, the at-tank analysis system to be interfaced to the sampler requires a sampling system for its waste stream and for its utility, structural, and shielding features.

A more detailed schematic of the sampling system is shown in Figure 1-2. The hose and reel design of the sampling system allows the RFD to be deployed at any waste depth in the tank. A steel cable around a pulley at the bottom of the segmented mast is used to control the depth of the sampling point (RFD and charge vessel) in the tank waste. Waste could be sampled at any depth in a waste batch or the fluidic pump components could be drawn up into the riser for temporary storage between sampling campaigns.

Figure 1-2. Mobile, Variable Depth Sampling System Showing Its Major Components and Interfaces for the RCRA Compatible Bottle-Filling Station and At-Tank Analysis System.

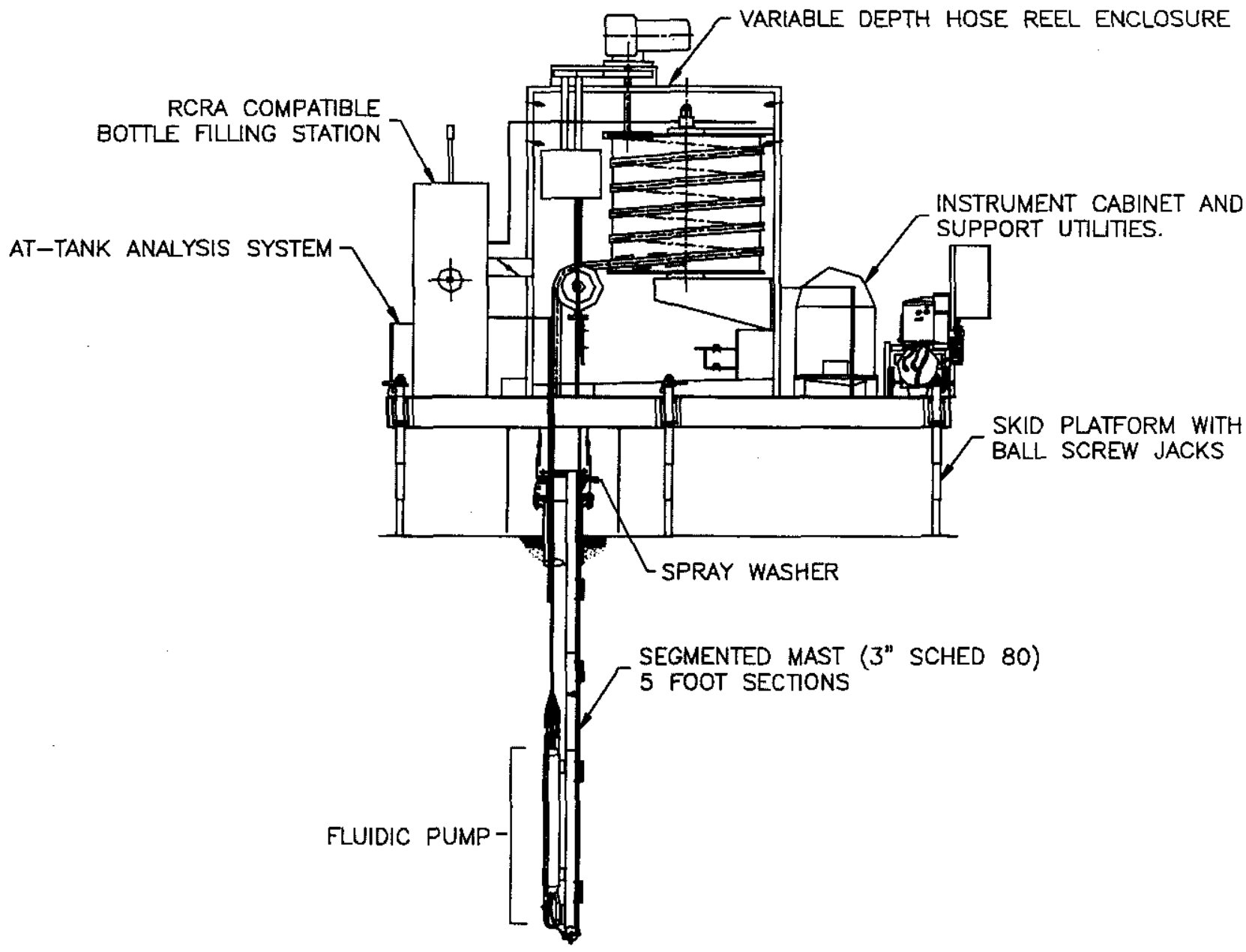




\section{HNF-2906 REV 1}

The bottle filling station is shown in more detail in Figure 1-3. Waste from the fluidic pump would flow through the bottle-filling chamber via one of two potential paths controlled by valves. The initial path is a loop that bypasses the sample reservoir. Changing the valve settings ports the waste through the reservoir and traps a waste sample in the reservoir. A sample bottle is placed under the reservoir and the reservoir is opened to fill the bottle with waste. The sample bottle and reservoir will be designed to produce samples that meet RCRA criteria for volatile and semivolatile organic waste materials. The sample bottle will contain a special bottle cap and interface with the reservoir to allow the sample bottle to be filled such that when the bottle is capped or sealed it contains no visible head space. After a sample bottle is filled, the residual waste in the reservoir is flushed out with water to reduce potential cross-contamination of waste materials between samples. The outside of the sample bottle also is flushed with water. During this process, the fluidic pump continues to pump waste through the loop around the reservoir. This continuous operation reduces the potential for waste plugging the pumping system. The filled and sealed sample bottle passes through the transfer chamber and into the packaging chamber. The transfer chamber, which is between the filling chamber and the packaging chamber, has sealed doors for contamination control. The samples is bagged and inserted into a steel pig in the packaging chamber. After the steel pig cover is replaced, the sample is removed for transport to the 222-S Laboratory.

Figure 1-3. Bottle-Filling Station Designed to Meet RCRA Criteria for Volatile and Semivolatile Organic Materials.

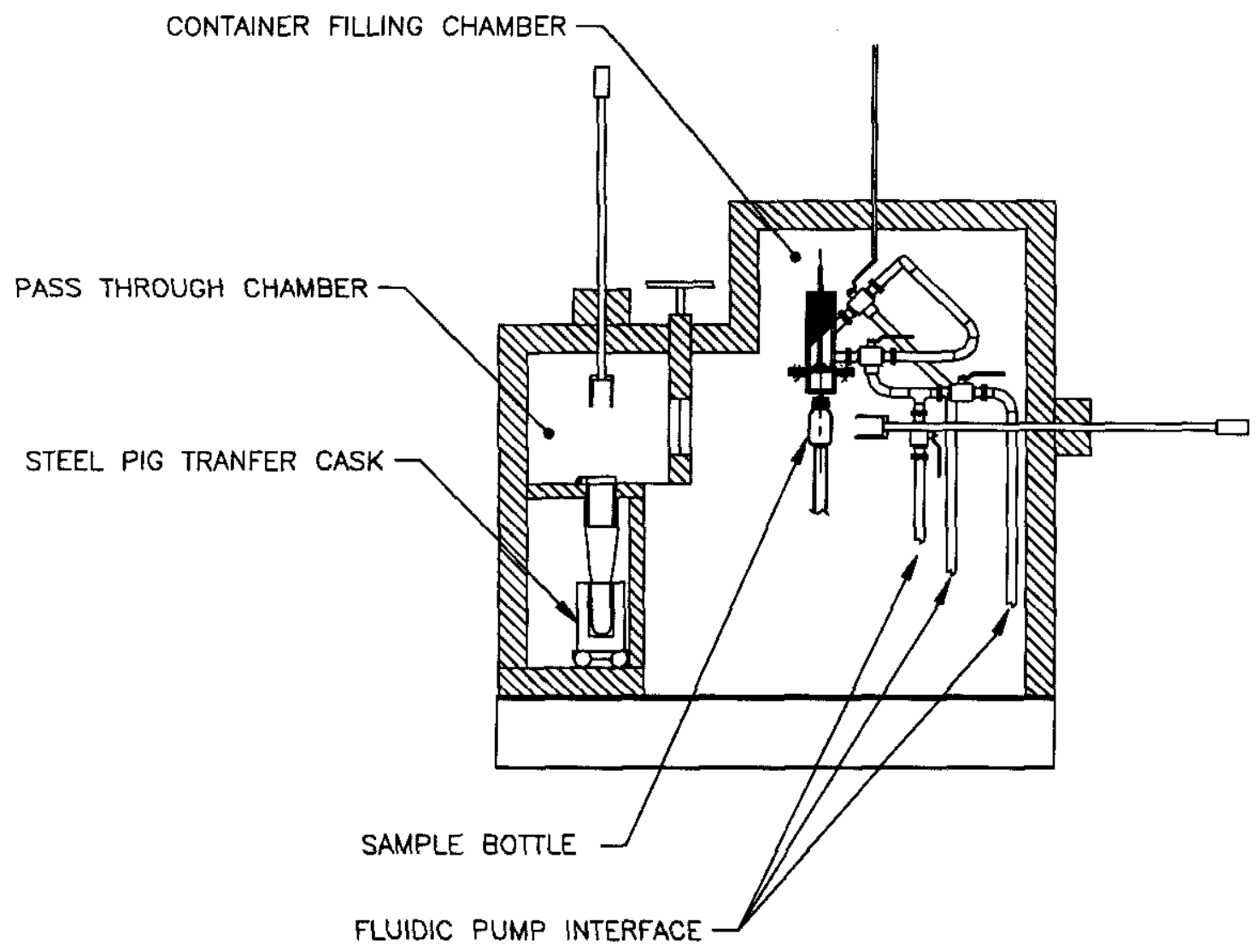


The three-chamber design of the sampling system allows contamination control and incorporates shielding to protect operators from exposure while they complete sampling operations. The sampling system chambers contain water flush and spray systems used to wash down the chamber interiors, the sample bottle handling manipulators, and the exterior surface of filled sample bottles.

After a tank sampling campaign is complete, the sampling system skid could be moved to another waste tank that has a new segmented mast and fluidic pump components installed in the sampling riser. The segmented mast and fluidic pumping components could remain in a tank for reconnection with the sampling skid for sampling at a future date or they could be set up for removal and disposal. The removal and disposal operation is independent from the sampling system and uses an A-frame hoist to remove the fluidic pump component and mast segments. The hoist is similar to that used in the disposal of drill string segments from core sampling. As these components are raised above the riser, a high-pressure spray system washes down the component surfaces. The mast segments are bagged and placed in burial boxes similar to those currently used for core string disposal.

A further refinement would be to add robust monitoring instruments to the bypass loop on the sampling system. The instruments would measure the physical, chemical, and radioactive properties of the waste. These measurements could be made at any depth within a waste batch and provide a data "profile" of the waste. This option provides the potential for obtaining process control data without removing and transporting waste samples to the 222-S Laboratory.

The fluidic pumping system has been used in the United Kingdom at nuclear installations for over 20 years. More than 400 systems have been installed with no failures. In addition, testing completed by AEAT on a fluidic pumping system in FY 1999 demonstrated that a fluidic pumping system can provide representative waste sampling for materials that contain over $30 \mathrm{wt}$ percent solids and have the viscosity of a water and sand mixture. (These test results are expected to be published early in FY 2000 by AEAT.)

The sampler system offers the following benefits:

- Ability to obtain a sample that meets RCRA criteria for volatile and semivolatile organic waste materials

- Ability to obtain representative samples from any size waste batch at any depth

- A proven sample pumping system design based on the fixed-depth sampling system technology being deployed and tested at the Savannah River Site

- An in-tank segmented-mast deployment system based on the core truck drill string operations and cable reel systems

- An enclosed system with reduced susceptibility to being delayed by bad weather conditions

- Reduction of difficulties (exposure levels, contamination, etc.) in acquiring multiliter quantities required by Interface Control Document (ICD)-19 and ICD-20 


\section{HNF-2906 REV 1}

- Ability to obtain representative samples while a tank's mixer pumps are operating.

- Greater ease of deployment and operation because of the self-contained skid design and the three-sealed-chamber design

- Ability for the equipment to be readily flushed and decontaminated because it will be designed with no crevices and with built-in water flush and drain systems

- Low operation and maintenance costs compared to core truck sampling

- Low cost for items requiring periodic replacement or replacement between sampling campaigns

- Low disposal costs for contaminated components (use of existing drill string burial box process)

- Inherent fail-safe operation where the sampler's system piping automatically empties its waste into the waste tank if an unplanned, sudden operational shutdown occurs during a sampling operation

- Exposure reduction through the disposal of all in-tank hardware rather than decontamination with reuse where high radiation dose rates would be experienced

- Reduction in health physics and safety work associated with the previous items

- A captive sampling system, dedicated to meeting the sampling needs of the privatization contract, without the availability issues currently associated with the core truck sampling systems

- Less susceptible to being delayed by bad weather conditions

- Adaptable to some process control, on-line monitoring for timely decision making

- Readily adaptable to baseline throughput rate of feed staging to the privatization contractor being increased (e.g., by a factor of 2 ).

The sampling system would provide greater ensurance that the CHG Team and DOE will not be required to pay "idle facilities" charges to the privatization contractor as a result of either of the following:

- Waste not being delivered on time

- Waste not being within envelope specifications.

\subsubsection{Comparison of Operations of Existing and New Sampling and Analysis}

Approach. The operational logic diagrams for the existing approach and the new sampling and analysis approach for LAW feed are shown in Figure A-1 in Appendix A. The logic diagrams for the two approaches are essentially the same except for the steps where "process control samples" are taken and analyzed. The logic blocks for process control sampling are highlighted 


\section{HNF-2906 REV 1}

and show two paths within the highlighted logic blocks. The existing approach will acquire process control samples with either grab or core sampling, then transport the samples to the 222-S Laboratory for process control analysis. The new approach would acquire process control data with the at-tank analysis system. Using the new concept will not require sample removal, transport, and laboratory analysis steps that the current process requires. Samples taken for process control include those taken after mixing, settling, or chemical adjustment.

Figures A-2 and A-3 in Appendix A compare one scenario of the operating schedule for a staging tank using the existing and new sampling analysis approaches. The time to complete the LAW sampling and analysis using the existing approach is about 181 days, compared to 141 days for the new approach. A key assumption in establishing this sampling and analysis time is that preliminary analysis takes 14 days at the 222-S Laboratory. Currently laboratory staff are working to identify alternative approaches to shorten this time. While this amount of time saving would not occur if the batch being staged required no adjustment or if another batch were already staged, such a time savings may occur sometime during Phase 1 . The operational logic diagrams for the existing and the new sampling and analysis approach for HLW feed are not yet available for inclusion in Appendix A. The processing sequence and logic for HLW feed are still being developed by the WFD, ICD-20, Integrated Products/Process Team (IPT).

The ICDs (ICD-19 and ICD-20) identify the sampling requirements that will be used for LAW and HLW.

\subsection{Low-Activity Waste Sampling. Grab sampling will be used. Immediately} following shutdown of the mixer pump, grab samples of waste will be obtained from nine different depths from below a single riser. The tank waste temperature will be measured at the time of sampling. The sample volume will meet that needed for the following:

- Analysis of the waste to support feed certification by DOE

- To provide a minimum of $1.5 \mathrm{~L}$ of sample both to BNFL and for archive.

Grab sampling is described in Section 1.2.2.1, "Existing Condition."

1.2.2.3.2 High-Level Waste Sampling. This description of HLW sampling is included for completeness. The sampling and analysis system is being developed for sampling both HLW and LAW. For HLW, grab or core sampling will be used. The sampling method used for each waste tank will be based on waste characteristics and capability of the sampling systems. Immediately following shutdown of the mixer pump the sampling will be completed:

- Grab sampling - Approximately equal volume grab samples will be obtained from every $61 \mathrm{~cm}(2 \mathrm{ft})$ of waste height below a single riser

- Core sampling - The core from the entire waste height will be taken.

The tank waste temperature will be measured at the time of sampling. The total sample volume for HLW currently depends on the solids content of the waste. The composite waste sample provided to BNFL will contain at least $200 \mathrm{~g}$ of solids. The solids content of HLW currently is expected to range from $10 \mathrm{~g} / \mathrm{L}$ to $200 \mathrm{~g} / \mathrm{L}$. (This means that $1 \mathrm{~L}$ to $20 \mathrm{~L}$ of sample volume may 
be required to meet this solids criterion.) The volume of sampled waste will provide tank waste materials for the following:

- Analysis of the tank waste to support feed certification by DOE

- A sample to BNFL

- A sample for archive.

1.2.2.3.3 Core Sampling. Core sampling is completed with a core sampling truck. Although some of the sampling operations require contact with the sampler, the operation is largely remote. The core sampling truck is set up over a riser and a core sampler is pushed or drilled into the waste to a predetermined depth. A sampler is $48 \mathrm{~cm}$ (19 in.) long by $2.5 \mathrm{~cm}$ ( $1 \mathrm{in}$.) in diameter, which produces a maximum sample volume of about $310 \mathrm{~mL}$. Sampling starts at the top of the waste and proceeds to the bottom. The sampling system contains water spray systems used to decontaminate the outer sampler surfaces. The system is designed to handle LAW and HLW materials. However, for extremely hazardous HLW, remote tools must be used to reduce the risk of contamination or exposure. This increases the sampling time.

The current ICDs also identify schedule limits based on the waste transfer day (WTD) established for a waste batch. DOE must provide representative samples, if requested by BNFL at least 30 days before the proposed transfer of the waste batch to BNFL and no more than 5 days after DOE completes sampling a waste batch.

1.2.2.3.4 Grab/Core Sampling Strengths/Weaknesses. The major strengths of the baseline grab and core sampling methods include the following.

- Both sampling methods are currently used and are tested and proven sampling methods with LAW and HLW waste tanks.

- Minimal operator training will be needed to support privatization contract sampling needs.

- A grab sampling campaign can be completed within a very short time. Core sampling requires a longer time as there are more issues to resolve with a tank, such as the completion of safety reviews (tank dome loading, exhaust impacts, access pathways, etc.).

- Grab sampling is flexible in sampling volume and location (random depth sampling with $500 \mathrm{~mL}$ sample bottles).

- Sampling can be done through a $10 \mathrm{~cm}(4-i n$.$) riser.$

The major weaknesses of the baseline grab and core sampling methods include the following.

- Sampling cannot be completed while the mixer pumps are operating. The mixer pumps must be shut down and the tank allowed to stabilize before sampling can begin. This 


\section{HNF-2906 REV 1}

may result in a sample that is not representative of the waste batch that will be transferred.

- Grab and core sampling cannot meet RCRA criteria for samples with volatile and semivolatile organics. Although the core truck samplers can be modified for RCRA sampling, modifications are not in current schedules. Equipment certification will be required, which may further delay system readiness.

- Using the grab and core sampling methods, operators may incur high dose levels. High exposures may occur with neutralized current acid waste (NCAW) in tanks with low solids content (approximately $40 \mathrm{~g} / \mathrm{L}$ ) when obtaining $200 \mathrm{~g}$ total solids content. Although either method can be modified to reduce this exposure somewhat, high exposures cannot be eliminated completely. These modifications (shielding, shielded gloves, remote tools, etc.) will reduce sampling speed.

- Core or grab sampling methods provide no options for obtaining process control data except through sampling extraction followed by laboratory analysis. Samples for process control data analysis can be taken only when the mixer pumps are off - when there is a risk that the sample is not representative of the waste that will be transferred.

- HLW feed batches can range from $200,000 \mathrm{~L}$ to $600,000 \mathrm{~L}$, which are waste depths of $0.49 \mathrm{~m}$ to $1.8 \mathrm{~m}(1.6$ to $6 \mathrm{ft})$. Obtaining separate samples from varying depths within this range will be difficult using grab and core sampling systems.

- Grab and core sampling truck equipment resources are limited. Core sampling resources can be increased by adding crew members. Two of the four core sample trucks are being retired in FY 2000, leaving two core truck systems to support all core sampling requirements. Required maintenance outages may take a truck off line for 3 months out of a year, while major upgrades could require an outage of up to 12 months (Aging of the core trucks is expected to require upgrades or new sampling equipment).

1.2.2.3.5 Sampling and At-Tank Analysis System Strengths and Weaknesses. The mobile, variable-depth sampling and at-tank analysis system will reduce risks and resolve issues that have been identified for the baseline grab and core sampling methods. The major strengths of the mobile, variable depth and at-tank analysis system include the following:

- The sampling system can sample and make at-tank waste measurements while the mixer pumps are operating. This will provide samples that are more representative of the waste batch that will be transferred and will allow operational data (tank mixing and settling and/or homogeneity assessment) to be obtained without removing waste from the tank and conducting laboratory analysis.

- At-tank analysis data (waste physical, chemical, and radioactive measurements) will be available for supporting process control decisions without the need for sampling and laboratory analysis. The sampling system is flexible so that a full-depth data profile can be obtained from any size (depth) waste batch. 


\section{HNF-2906 REV 1}

- Waste samples for waste batch validation can be obtained at any depth in any size waste batch (samples can be obtained over a depth range of over $11 \mathrm{~m}[35 \mathrm{ft}]$ of waste). Samples can be taken randomly at any waste depth and multiple or repeat samples can be obtained.

- Large-volume waste samples can easily be obtained with low operator exposure. The sampling system will fill the current $500 \mathrm{~mL}$ sample bottle and the steel pig transport system. Shielding and remote sampling operations produce low operator dose levels. The sampler design is based on the HLW range required by the privatization contract, which includes waste from tank 241-AZ-102.

- The $500 \mathrm{~mL}$ sample bottles with specially designed caps meet RCRA criteria for volatile and semivolatile sample materials. The sample bottles will be sealed and will be 100 percent full with no visible head space when inverted.

- The sampler has the potential for reduced outage time and for reduced maintenance and operating costs as compared with the core truck sampling system.

The sampling system is skid mounted with self-contained utilities so it can be crane deployed in any waste tank with an available $30 \mathrm{~cm}$ (12-in.) riser. Deployment in a smaller diameter riser is preferred and will be pursued in the system design. No surface access road to the riser is required and no potential modifications to the tank farm utility system will be required.

The major weakness of the proposed new sampling and at-tank analysis system is as follows.

- Although the mobile, variable-depth sampling method uses proven design features (fluidic pumping system and core sample drill-string-like handling), development, testing, safety assessments, and readiness reviews will be required for hot deployment.

\subsection{SCOPE}

This document contains the missions, objectives, strategies, planning assumptions, proposed deployment scenario, schedule, funding needs, and proposed funding sources to support the demonstration and deployment of a rapid tank waste sampling and at-tank analysis system in the LMHC LAW and HLW feed staging and delivery tanks.

\subsection{MISSION AND OBJECTIVES}

\subsubsection{Mission}

The mission of this CHG Characterization and Safety-Representative Sampling Project, as it is called in EM-50's RLO-8-WT-22 Technical Task Plan, is to develop and demonstrate a capability for rapidly taking and analyzing representative samples to support staging LAW and HLW feed successfully for the privatization contractor, safely, cost effectively, and with a minimum impact on tank space. The mission of this project supports the ORP's mission: "to 


\section{HNF-2906 REV 1}

store, treat, immobilize, and dispose of the highly radioactive Hanford Site waste in an environmentally sound, safe, and cost-effective manner" (Swita 1998).

The sampling system project supports the mission of the Assistant Manager, Waste Processing and Disposal, to treat, immobilize, store, and dispose of current and future highly radioactive Hanford Site tank waste in an environmentally sound, safe, secure, and cost-effective manner.

The sampling system project more specifically supports the mission of the Assistant Manager, Storage and Retrieval, and its Characterization Project, which provides the following functions:

- Characterization of the tank waste to verify that the feed meets specification

- Characterization of the tank waste before shipment to BNFL to verify that the feed meets specification (Erickson 1999).

\subsubsection{Objectives}

The goals of the sampling system project are as follows:

- Achieve baseline sampling needs for LAW and HLW feed staging and delivery with assurance; this implies ensuring that schedule float exists. This float will enable the schedule to accommodate an iteration in the logic (e.g., the mixing is not adequate and more mixing is needed; the contents don't meet solids specification and settling must be allowed for the LAW; the contents don't meet chemicals specification and some material must be pumped out and new feed material added, mixed, sampled, and analyzed) that will be used to support feed delivery.

- Be able to accommodate sampling outages caused by any bad weather outages (e.g., from wind, snow, cold, and lightning).

- Reduce ALARA exposure and potential for personnel contamination.

- Accommodate sample size and quantities (e.g., $5 \mathrm{~L}$ ) sufficient to meet CHG/PHMC Team laboratory analysis needs, privatization contractor needs, and CHG/PHMC Team archiving needs.

- Phase into use and into the baseline in a way that supports risk reduction and does not increase risk (e.g., schedule risk).

The goals of this project also support the fundamental objectives of the ORP Assistant Manager, Waste Processing and Disposal (Erickson 1999). These objectives include the following:

- Minimize environmental, worker safety, and public health risks

- Minimize costs 


\section{HNF-2906 REV 1}

- Maximize regulatory compliance, including meeting the Hanford Federal Facility Agreement and Consent Order (Tri-Party Agreement) (Ecology et al. 1996) and National Environmental Policy Act of 1969 (NEPA) Record of Decision obligations

- Develop stakeholder confidence and acceptance

- Develop and deploy technology to solve Site and DOE Complex problems

- Design, construct, and operate facilities necessary to feed waste, immobilize waste, and store the immobilized waste form within the cost and schedule baseline.

The Representative Sampler Project supports the two highest priority ORP criteria:

- Activities that directly support or provide the basis for the requirements of privatization will have the highest priority. Activities that reduce environmental, worker, or public health risk will have priority.

The guidance further states

"Technology development will be managed to execute the disposal strategy and support the resolution of user-identified problems or issues. Technology development opportunities with EM-50 Technology Development Programs will be leveraged wherever possible to achieve common goals. Technology activities that support core competencies and alternate path planning, regardless of funding source, will be specified in the integrated technology Section of each project description.

"Technology activities and supporting infrastructure priorities will be incorporated into the MYWP development process, regardless of funding source. Programs and projects will develop their technology needs through a technique that incorporates analyses of the risk involved. Areas of risk requiring mitigating technology shall be systematically identified through the Site Technology Coordination Group needs process. Planned technology activities that support waste disposal will be separable for monthly reporting purposes. Integration of technology development/deployment activities will be documented at the cost account level at a minimum, with clear links to the TWRS Logic, the integrated schedules showing technology insertion points, and the risk management system."

- The risks that can be mitigated by the Representative Sampler Project are identified in Appendix B. The Site Technology Coordinating Group-Tanks Subgroup has reviewed and approved the technology needs statement (RL-WT-09) associated with this project each year. The technology insertion point for this project is Milestone T01-01-108, contained within the Characterization Project, TW01 baseline. 


\section{HNF-2906 REV 1}

This page intentionally left blank. 
HNF-2906 REV 1

\subsection{STRATEGIES}

\subsection{DEVELOPMENT STRATEGY}

The development strategy uses a segmented approach that focuses on the sampler system and the at-tank analysis system independently for the first years of development. This facilitates development of the sampler to proceed as fast as possible, without being delayed by various delays associated with the at-tank analysis work. Deployment of the sampler also could occur independently, so its benefit can be gained even if the development of the at-tank analysis capability lags or is unsuccessful. The development of the analytical system may lag because of procurement issues as well as because the sampler's development is further along and the analytical system may prove to be more technically challenging.

The development strategy for the sampling system will use a technology that has been successfully demonstrated in the past by AEAT and BNFL, and will extend this technology to the present application and thus increase the likelihood of success. Fluidic sampling was chosen as the preferred technology because it has been successfully used in England for a number of years. It is a highly reliable technology that has the capability of being designed to function under adverse weather conditions. In FY 1998 the concept of a nested group of eight fixed-depth fluidic samplers capable of being deployed in a single $30 \mathrm{~cm}$ (12-in.) waste tank riser was chosen as the technical approach. Such a system would be capable of operating under adverse weather conditions, require only a small development effort because fixed-depth samplers have been used in the past, and would minimize the time needed to obtain the samples because the sampling apparatus would not have to be moved. The application of this system would benefit from the deployment of the fixed-depth sampler at the Savannah River Site for waste similar to that at the Hanford Site. The development strategy broadened in FY 1999 to focus not only on the AEA bottle-filling technology, but also to identify a RCRA-compliant bottle-filling methodology This compliance became a requirement in FY 1999.

Later in FY 1999 the WFD strategy evolved to include the capability to stage and deliver feed from four different tank farms, AN, AZ, AY, and the previously identified AP farm. The DOE guidance also revised the dates for hot startup for LAW and HLW pretreatment to April 2006, HLW vitrification to February 2007, and LAW vitrification to January 2008. This has resulted in a mobile, variable-depth concept emerging as the preferred sampler concept for deployment. The capital cost associated with the mobile unit would be significantly less than the many permanent units that would be required with the former strategy. The mobile unit incorporates design and operating experience with the present Hanford Site core sampling trucks with the improved technology of the power fluidic approach.

The development strategy will still consist of cold validation testing of the fluidic system concepts at AEAT facilities. The design and fabrication of the sampler platform will be handled by a procurement through National Energy Technology Laboratory (NETL) with a commercial vendor. AEAT will be contracted for fabrication and preacceptance testing of the power fluidic hardware portion of the sampler system. The final deployable system then will be tested cold at the Hanford Site under conditions similar to what it will experience in the actual operations. The 


\section{HNF-2906 REV 1}

system then will be tested hot in an actual double-shell tank at the Hanford Site. Hanford Site personnel will conduct these tests with support from AEAT personnel.

The development of the at-tank analysis system will focus on process control. Analysis will be required to determine if contractual confirmatory samples should be taken. Ideally, confirmatory samples would be taken if the tank is well mixed, if the tank is adequately settled (if required), and if the tank is likely to be within the specification envelope without further adjustments. The focus of the at-tank analysis will be to determine if the tank is well mixed or is adequately settled. The emphasis will not be to determine if the tank is within the privatization contract feed envelope specifications. This would be extremely difficult to do without a full suite of chemical analyses. Aside from the cost of the equipment to do these analyses, the operability and maintainability of the instruments necessary to do these chemical analyses in the field is expected to be quite poor.

The strategy will be to select a limited number of simple, well-established technologies that can be successfully implemented in the field to measure chemical, physical, and radiological properties. Successful implementation will be judged not only on our ability to develop and install the hardware, but on the operability (reliability, availability, and maintainability) of the hardware in the field. The at-tank measurement data may not need absolute accuracy, but only relative accuracy for indicating tank mixing or settling status. Other potential measurements include neutron measurements needed to ensure the criticality safety of a waste batch.

\subsection{DEPLOYMENT STRATEGY}

The strategy for deploying the sampler and at-tank analysis systems is to use a phased approach By selecting early deployment phases that have a high likelihood of success and a relatively high payoff, the phased approach maximizes the benefits to DOE. Generally, the goal of development and deployment will be to try bringing a capability to operational readiness with significant benefit as soon as possible. Additional capability providing additional benefit will be added in stages.

The first phase of the strategy is to develop and deploy a fluidic sampler system capable of sampling either LAW or HLW. Assuming successful demonstration of the system, a mobile, variable-depth sampler will be deployed. Which tank is selected first for deployment will depend on the schedule for development, the schedule for implementing privatization, the requirements for feed sampling as they are defined by ICD-19, Low-Activity Waste Feed, and ICD-20, High-Level Waste Feed, waste acceptance requirements, other privatization contract requirements that may be adopted, and the interference caused by other construction activities in the tank farm. If the sampler can be used for the selected feed staging tanks without adversely affecting the baseline efforts to support privatization contractor hot start-up, the sampling capability will be deployed in those tanks first. If an adverse impact would result, the sampling capability will be deployed on another feed source tank first. After the sampling capability is demonstrated and any improvements defined and perhaps tested, the sampling capability would be deployed on other tanks. Samples may be taken from some tanks using grab samplers and from other tanks using the mobile, variable-depth sampler. 


\section{HNF-2906 REV 1}

The source tanks selected will depend on the development schedule and the privatization schedule. The source tank selected will be from the HLW feed staging tanks or the LAW feed staging tanks meeting Envelope A because only this group will require mixer pumps to operate during sampling. Because the plans are to decant the liquid from the Envelope A source tanks and dilute it to fill the first staging tank from a given source tank, this part of the source tank cycle would not allow testing of the sampler while mixing. Therefore, the sampler must be tested in the second half of the source tank cycle during which water will be added to the tank and the tank contents mixed to dissolve the solids in the source tank before filling the second staging tank from a given source tank.

The second phase of the deployment strategy will be to bring the at-tank analysis system on line. This analysis of the waste (physical, radionuclide, and chemical) will be done to enhance the feed processing schedule to ensure that the waste is ready for the confirmatory samples to be taken and analyzed at the 222-S Analytical Laboratory (and by the privatization contractor) to ensure that the waste is ready for transfer to the privatization contractor. Process steps that can be monitored with this capability include monitoring to know when sufficient mixing has occurred in the feed staging tank and monitoring to know when sufficient settling has occurred if settling is needed to meet the feed specification. The first and second phases may be combined if the at-tank analysis capability is ready for deployment along with the first phase. In the plan portrayed in Chapter 4 (e.g., in Figure 1-3), these phases are assumed to be combined.

The third phase will be to bring sampling (and at-tank analysis) to the source tanks in the 200 West Area, such as 241-SY-102, before initiating a cross-site transfer. This will ensure successful cross-site transfer of either LAW feed, salt well liquor pumping should it extend beyond the current finish date (April 2004) for case 4 (See HNF-235-B), or Phase 2 single-shell tank retrieval.

\subsection{FINANCIAL STRATEGY}

The funding strategy will be to seek funds from EM-50 to complete the system development and support the initial part of the deployment of the first prototypical system. EM-30 cofunding increases progressively as the project continues. By FY 2003 the EM-50-funded cold testing is giving way to EM-30-funded deployment activities. EM-30 funds will be sought to complete deployment of the first prototypical system and subsequent deployments. EM-50 funding is coordinated through the TFA, which involves other EM-50 programs as it identifies opportunities for them to participate. In FY 1998 and FY 1999, the TFA involved multiple EM-50 programs in the sampler system development activities. The International Grants Program is being used to support the development of the sampling system concept. The Tanks Focus Area Program itself is supporting the integration of these systems into the Hanford Site tank system. The Characterization, Monitoring, and Sensor Technology (CMST) Crosscutting Program and the Robotics Cross Cut Program are supporting the development and design of the first prototypical analytical system. In FY 2000 and FY 2001, the International Grants Program, the NETL at Morgantown, and the TFA will support the design and fabrication of the first prototypical sampler system. 


\section{HNF-2906 REV 1}

Every attempt should be made to hold the funding profile established in this document, even if the privatization schedule slips, so that the sample and analysis systems can be installed earlier in the privatization schedule. The sample and analysis system demonstration schedule associated with this funding profile should be revised if the privatization schedule slips so the first system can be used on a source tank earlier in the sequence of source or staging tanks. 
HNF-2906 REV 1

\subsection{STRATEGIC ASSUMPTIONS}

The demonstration and deployment of a mobile, variable-depth sampling system are based on the following strategic assumptions.

- The mobile, variable-depth sampling system is a suitable alternative method to grab sampling and core sampling as discussed in Claghorn et al. (1997) to support the staging of LAW and HLW for Phase 1 Privatization. (See also Appendix D.)

- The CHG/PHMC Team will maintain, at a minimum, the capability to sample, stage, and deliver feed from the $\mathrm{AN}, \mathrm{AZ}, \mathrm{AY}$, and $\mathrm{AP}$ tank farms.

- The sampler will be able to take samples at many different depths, regardless of the degree of fullness of the waste tanks and be capable of operating while the tank is being mixed.

- ORP cannot afford to permanently deploy a sampler system in each tank that will need to be sampled using this equipment and from which feed will be staged. Therefore, the system, or at least the portion involving the major expense, will be capable of being moved economically from tank to tank.

- While the current baseline schedules of the CHG/PHMC Team and BNFL call for HLW treatment to begin before LAW treatment, deployment of the mobile, variable-depth sampling system will be capable of supporting an alternative schedule that has LAW treatment preceding $\mathrm{HLW}$ treatment.

- BNFL will perform sludge washing of the HLW feed in their WTP facility

- When it is deployed, the mobile, variable-depth sampler system will be a worthwhile alternative to the baseline method, even if the date of deployment in support to the staging of the waste is after the hot startup of the RPP WTP.

- The mobile, variable-depth sampling system is worthwhile, separable and apart from the at-tank analysis capability.

- The at-tank analysis capability will be a worthwhile addition to the mobile, variabledepth sampler system when it is deployed, even if the date of deployment in support of waste staging is after the deployment of the sampling system.

- The mobile, variable-depth sampler system will benefit from the experience of deploying a fixed-depth fluidic sampling systems that is currently under way at the Savannah River Site.

- The Idaho National Environmental and Engineering Laboratory and the Savannah River Site will benefit from the development and deployment of the mobile, variable-depth sampling system at the Hanford Site. 


\section{HNF-2906 REV 1}

- The funding strategy for the mobile, variable-depth sampler system efforts at the Hanford Site includes strong EM-50 funding with limited EM-30 cofunding before a technology insertion point at the conclusion of cold testing, and strong EM-30 funding followed by progressively more limited EM-50 cofunding. The EM-50 funding involves TFA funding of the CHG/PHMC Team together with International Grants funding for AEAT support to adapt their power fluidic technology, CMST support using NETL to bring in commercial industry expertise for at-tank analysis, and the Robotics program to integrate the sampling technology with the at-tank analysis systems. EM-30 cofunding covers project integration with Hanford Site needs and deployment requirements, hot testing, and deployment of the first and subsequent systems.

- The at-tank analysis system will be used to expedite deciding whether a feed batch in the feed staging tank is ready to have the confirmatory samples taken for 222-S Laboratory analysis and for providing a split sample to BNFL in accordance with the privatization contract. The system will not be used to perform analyses that determine, for contractual purposes, that the feed batch is within specification and is ready to be transferred to the privatization contractor's feed tank.

- Adapting the mobile, variable-depth sampler system to be an alternative method to grab sampling and core sampling of tank waste in the 200 West Area (e.g., in

tank 241-SY-102) to support the cross-site transfer of tank waste to the 200 East Area is not part of the current project. This task will be considered a later phase of the project and use technology and lessons learned from this project. 


\subsection{DEPLOYMENT PLAN}

Since FY 1998 the LMHC/PHMC Team, together with AEAT, has undertaken the development of the fluidic sampling system. This development effort has enabled the Hanford Site to incorporate AEAT's vast fluidic pumping and sampling system experience in Europe and their recent and current work on fixed-depth sampling at the Savannah River Site. In parallel with this sampler development, Pacific Northwest National Laboratory, through the Robotics Cross Cut Program, has worked with the LMHC/PHMC Team to develop analytical concepts that would apply for at-tank analysis in conjunction with the fluidic sampler. A systems integration task enabled the emerging sampler and at-tank analysis concepts to be coupled with the user requirements to create a Level 2 Component Specification.

\subsection{DEPLOYMENT LOGIC}

Figure 4-1 shows the deployment logic for the mobile, variable-depth sampler system including the at-tank analysis system. The funding amount and proposed source of funds is identified for each logic block. Figure 4-1 includes a time line to indicate when the funds are needed and when the work will be performed for each logic block activity. Sections 4.1.1 through 4.1.23 describe the logic block activities individually.

\subsubsection{Sampler Development}

The sampler development task at the Hanford Site included developing the concept of the nested, fixed-depth sampler and conducting proof-of-principle testing in FY 1998 and conducting concept-validation testing in FY 1999 for a full-height test unit. The full-height test unit

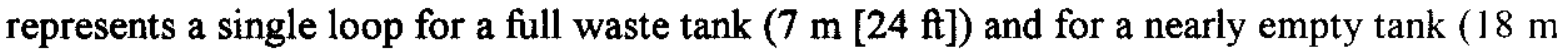
[59 ft]). Sand/water and kaolin/water mixtures were used as simulants. The FY 1998 test results are summarized in two AEAT documents, Design, Fabrication \& Demonstration of a Nested Fixed Depth Fluidic Sampler (AEAT 1998a) and Nested Fixed Depth Fluidic Sampler Supplementary Testing (AEAT 1998b). The sampler development preparation in FY 2000 will include AEAT issuing a test report covering their FY 1999 testing of a prototypical sampling channel, and their FY 2000 testing to demonstrate RCRA-compliant bottle-filling techniques. 


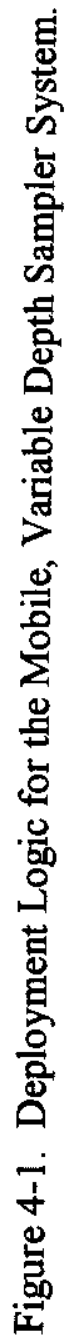

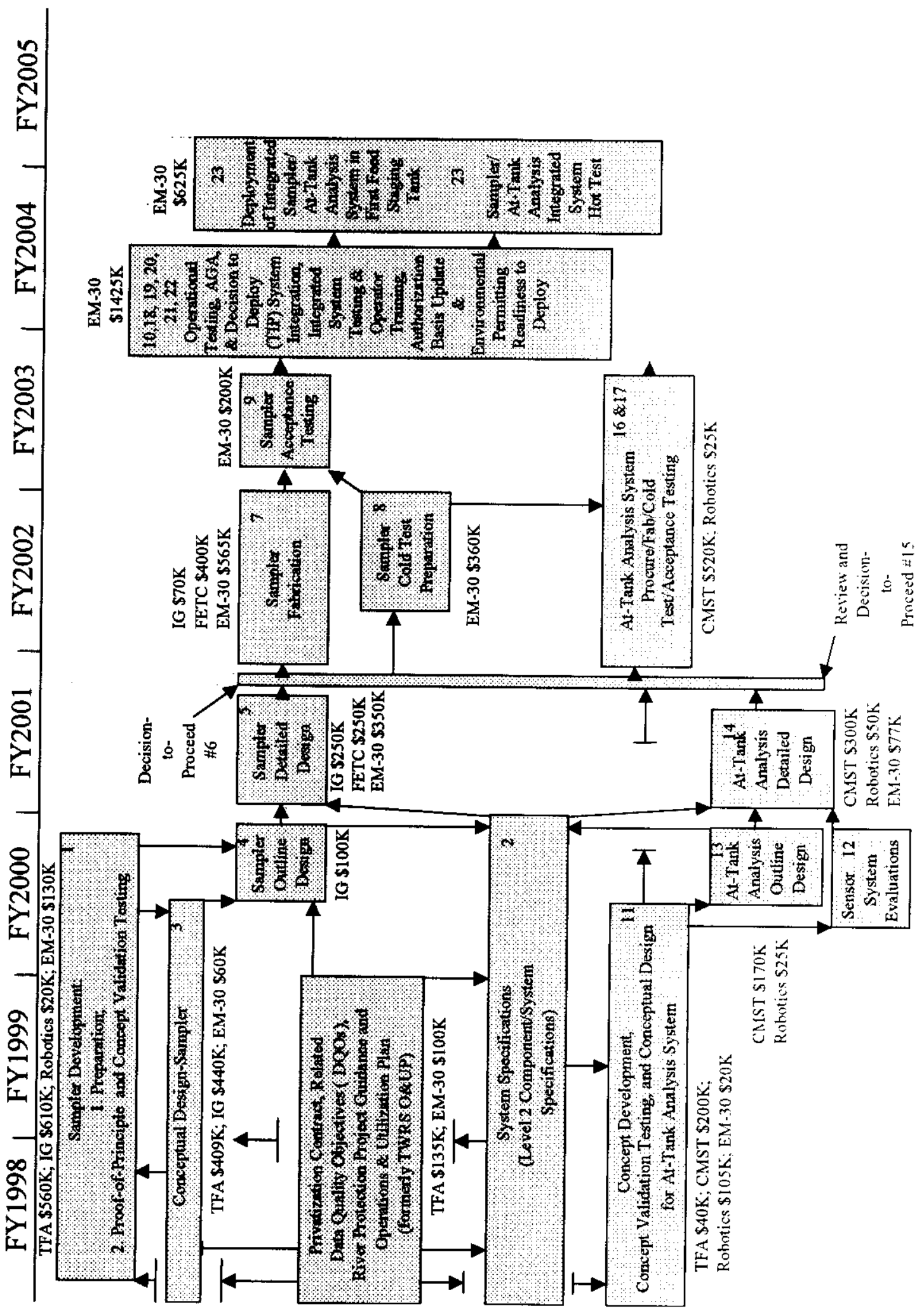




\section{HNF-2906 REV 1}

\subsubsection{System Specifications (Level 2 Component/ System Specifications)}

This specification establishes the functional and performance requirements for a sampling system that will support the privatization contract (Tank Waste Remediation System Privatization Contract DE-AC06-96RL13308, Mod. No. A006, 1996, U.S. Department of Energy, Richland, Washington, with BNFL Inc.) in the final disposal of Hanford Site HLW and LAW. The document provides a comprehensive list of functions, requirements, and specifications to support the design, development, performance assessment, and testing of a sampling system that will meet the privatization contract requirements. As these design and testing activities proceed, additional criteria will be available for this Level 2 specification, including requirements and criteria identified from the hazards analysis that will be completed on the design of the prototype sampling system.

This specification also will contain environmental and physical criteria for hardware operating inside the tank farm, criteria for in-tank operation, and criteria for using Site-approved casks to transport samples to the 222-S Laboratory and to the privatization contractor. The existing authorization basis will not be imposed as a requirement on the sampler. Rather, a hazards analysis and subsequent safety evaluations will be completed to determine if the existing authorization basis is adequate or will need adjustment. Any necessary adjustment in the authorization basis and update of the safety documentation will be completed as part of this deployment.

This will allow the sampler system to operate reliably and relatively maintenance free through $30 \mathrm{~cm}$ (12-in.) risers in the Hanford Site tanks (because some of the tanks do not have this size of riser available, development will be directed to a system that can potentially be deployed in a $15 \mathrm{~cm}$ [6-in.] riser). Waste samples will be provided to the privatization contractor and to the 222-S Laboratory for analysis.

In FY 1998 HNF-3483, Rev. 0, Preliminary Level 2 Specification for the Nested, Fixed-Iepth Fluidic Sampler (Reich 1999a), was drafted with specifications for a nested, fixed-depth sampler system. The document was issued in February 1999. In May 1999, Revision 1 was issued. Revision 1 included specifications for the at-tank analysis system and RCRA-compliant sampling criteria. Revision 1 also incorporated results of AEAT's 1998 validation testing

In FY 2000 the Level 2 Specification will be updated to include the information found in HNF-4545, Alternative Generation and Analysis Study for a Waste Sample Container Filling System for the Nested, Fixed-Depth Sampling System (Reich 1999b), and the associated AEA testing of bottle-filling concepts as defined in HNF-4883, Phase II Test Plan for the Evaluation of the Performance of Container Filling Systems (Reich 1999c).

\subsubsection{Conceptual Design-Sampler}

In FY 1998 and early FY 1999 AEAT prepared a conceptual design for a nested, fixed-depth sampling unit capable of sampling LAW from the AP-102 and AP-104 tanks at various depths. 


\section{HNF-2906 REV 1}

This sampler used power fluidics to pump and deliver the waste into a $500 \mathrm{~mL}$ bottle from 8 fixed tank elevations and was configured to fit within a $30 \mathrm{~cm}$ (12-in.) waste tank riser.

\subsubsection{Sampler Outline Design}

In FY 1999 AEAT embarked on the next phase of sampler system design to include preliminary hazard and reliability and availability assessments, and a cost estimate and project schedule for detailed design, fabrication, testing, and delivery of the prototype system in accordance with HNF-3483, Rev. 0 (Reich 1999a). Midway through FY 1999 this activity was delayed to address concerns about capturing representative samples in the sample bottle for low-viscosity liquid containing large particles and for RCRA-compliant samples containing volatile organics. This outline design activity is scheduled to resume in FY 2000 using the results of the HNF-4545 AGA (Reich 1999b) for the waste sample container filling system. At the end of FY 2000 a design review will be completed, and recommendations will be prepared that include corrective actions needed to proceed to the detailed design.

\subsubsection{Sampler Detailed Design}

In FY 2001 the NETL will issue a call for a design and fabricate contract with a commercial vendor that implements private contracts for DOE. Early in FY 2001 a preliminary hazards assessment will be completed; and HNF-2906, the Deployment Strategy and Plan, will be updated. The design and fabrication contract will be awarded in FY 2001. At the conclusion of the design phase, a design review of the sampler will be held in conjunction with the design review of the at-tank analysis equipment.

\subsubsection{Decision-to-Proceed}

In FY 2001 a review of the detailed sampler design will be made against the programmatic requirements for feed staging to support privatization. This review will be to reaffirm that the RPP Waste Retrieval customer still desires to proceed with this alternative to the grab sampling and core sampler baseline. The decision will be documented in the approved FY 2001 RPP MYWP.

\subsubsection{Sampler Fabrication}

In FY 2002 the vendor will fabricate and performance test the mobile, variable-depth sampler under the NETL procurement. The power fluidics pump and sample station for the platform will be fabricated, probably by AEAT. Robotics will assist $\mathrm{CHG}$ with inspecting the hardware for acceptance. 


\section{HNF-2906 REV 1}

\subsubsection{Sampler Cold Test Preparation}

In FY 2002 CHG will prepare the cold test facility to receive the prototype sampler and revise the hazards assessment. The Engineering Task Plan (HNF-2056) and the Deployment Strategy and Plan (HNF-2906) will be revised.

\subsubsection{Sampler Acceptance Testing}

In FY 2003, using only EM-30 funding, a test plan will be prepared, the mobile sampling system will be installed at a cold test facility at the Hanford Site, and cold testing will be completed.

\subsubsection{Sampler Operational Testing}

In FY 2003 the operational test plan will be prepared. The mobile sampling system will be installed at a cold test facility at the Hanford Site, and cold testing of the sampler will be completed. This will be supported by EM-30 funding.

\subsubsection{Concept Development, Concept Validation Testing, and Conceptual Design for the At-Tank Analysis System}

In FY 1998 preliminary requirements and concepts for the at-tank analysis system were formulated. In FY 1999 NETL prepared a statement of work and selected a vendor to perform the conceptual design and testing, and the design and fabrication of the equipment. Early in FY 2000 CHG will issue At-Tank Low-Activity Waste Feed Homogeneity Analysis Verification, which will identify potential tank waste chemical, physical, and radioactive properties for sensing by the at-tank analysis system. The data from these sensors will be used to determine homogeneity of LAW feed. This document will serve as updated input to the vendor. In FY 2000 the vendor will identify analytes and/or physical properties for at-tank analysis. The vendor then will complete the conceptual design of the at-tank analysis system.

\subsubsection{Sensor System Evaluations}

In FY 2000 the vendor will conduct performance testing of sensors and instruments needed to demonstrate the required accuracy, sensitivity, precision, and compatibility with at-tank functions and design criteria requirements.

\subsubsection{At-Tank Analysis Outline Design}

The at-tank outline design will be completed in FY 2000. This design will include preliminary versions of process flow diagrams, equipment layout and arrangement, process and instrumentation diagrams, and engineering calculations; preliminary hazards identification and evaluation; and a preliminary reliability, availability, and maintainability (RAM) analysis; cost estimate; and project schedule. 


\section{HNF-2906 REV 1}

\subsubsection{At-Tank Analysis Detailed Design}

In FY 2001 the commercial vendor funded by CMST will proceed with the detailed design of the at-tank analysis system. Early in FY 2001 a preliminary hazards assessment will be completed for the at-tank analysis system, as well as for the other components of the integrated sampling and at-tank analysis system (see task 4.1.5). The final design package will include process flow diagrams, equipment layout and arrangement, process and instrumentation diagrams, engineering calculations, an updated hazards identification and evaluation, updated RAM analysis, and an updated cost estimate. At the conclusion of the design phase, a design review of the at-tank analysis system will be held in conjunction with the design review of the sampler and sampler platform.

\subsubsection{Review and Decision-to-Proceed}

In FY 2001 this activity will be done in conjunction with the decision to proceed described in Section 4.1.6. The detailed at-tank analysis design will be reviewed against the programmatic requirements for feed staging to support privatization. This review will be to reaffirm that the RPP Waste Retrieval customer still desires to proceed with this part of the alternative to the grab sampling and core sampler baseline. The decision will be documented in the approved FY 2001 RPP MYWP.

\subsubsection{At-Tank Analysis System Fabrication}

In FY 2002 the vendor will procure all necessary materials and equipment to implement the final design specification into an integrated at-tank analysis system.

\subsubsection{At-Tank Analysis System Acceptance Testing}

In FY 2003 the vendor will prepare a plan for installing the at-tank analysis system at a Hanford Site test facility. The vendor will revise the hazards identification and analysis document. The vendor will submit a laboratory acceptance test implementation plan detailing all aspects of the tests to be performed. After approval by CHG, the vendor will conduct the tests, analyze all performance data, and submit a test report.

\subsubsection{At-Tank Analysis System Operational Testing}

In FY 2003 the operational test plan will be prepared for the at-tank analysis system. The system will be installed at a cold test facility at the Hanford Site, and cold testing will be completed

\subsubsection{System Integration}

In FY 2003 the sampler system, including the sampler platform and the at-tank analysis system, will be integrated in the cold test facility. 


\subsubsection{Integrated System Testing and Operator Training}

In FY 2003 operational testing will be complete at the cold test facilities using simulated waste materials. These tests will verify the operation and performance of the systems. Operator training will be completed. Modifications will be made based on lessons learned from this testing.

\subsubsection{Authorization Basis Update and Environmental Permitting}

In FY 2003 issues related to the authorization basis and environmental permitting will be identified. These issues will be addressed before hot deployment in FY 2004.

\subsubsection{Hot Installation Readiness Review and System Preparation}

In FY 2003 a hot deployment readiness review will be completed to assess the status of the systems for hot deployment.

\subsubsection{Hot Installation and Testing}

In FY 2004 hot testing will be conducted and the results analyzed. Based on these results, a decision to proceed with operation of the integrated sampling system and fabrication of additional units for use elsewhere in the waste feed staging arena will be made.

\subsection{PLANNING ASSUMPTIONS}

The demonstration and deployment of a mobile sampler system are based on the following planning assumptions (Swita 1998).

- CHG will be able to stage waste feed at 1,100 units annually until February 2018 and 2,200 units annually for the rest of the extended Phase 1 . CHG will be able to stage HLW feed at 120 canisters per year until February 2018 and 480 canisters per year thereafter (Swita 1998). CHG will consider that DOE may be required to pay a penalty of approximately $\$ 2.5$ million per day for idle facilities (Swita 1998).

- Privatized hot operations are assumed to start in April 2006 for LAW and HLW Pretreatment, February 2007 for HLW vitrification, and January 2008 for LAW vitrification (Swita 1998).

- In addition to those needed to meet the CHG Team requirements, waste certification samples and BNFL samples will be required in accordance with ICD-19 and ICD-20. Generally, a few liters of samples will be required to satisfy CHG Team and BNFL needs (rather than the $100 \mathrm{~mL}$ assumed in the AGA [Claghorn et al. 1997]). 


\section{HNF-2906 REV 1}

- Large mixer pumps will be installed in the feed staging tanks, and samplers will be able to operate while these pumps are operating (EAMCS.120.C.10, EAMCS.110.45, and EAMCS.160.A52 [FDH 1998]).

- As a result of mixer pump operation in the feed staging tanks, no radial (i.e., horizontal) variability exists in the waste composition; therefore, sampling at a single riser location is adequate.

- The vertical variability of the waste as measured by the sampling system at multiple depths does not change significantly during the time required to take the full set of samples.

- CHG may have to take a representative sample of each batch of HLW waste in a feed staging tank where a batch size could be as small as $200,000 \mathrm{~L}$ (about 50,000 gal), which corresponds to about $46 \mathrm{~cm}(1.5 \mathrm{ft})$ of waste in the tank

- A riser $30 \mathrm{~cm}$ (12 in.) in diameter or larger will be available with appropriate surface space to support the deployment of a sampling system into any waste tank that will be used as the transfer point to BNFL and where samples will be required by the privatization contract.

- The new sampling and analysis approach will have the benefits described in Section 1.2.2.2.

\subsection{DEVELOPMENT AND DEPLOYMENT SCHEDULE}

The schedule for the development and deployment of the mobile, variable-depth sampling system with the at-tank analysis system is shown in Figure 4-2. This relatively high-level schedule shows the design, fabrication, and cold testing of the mobile sampling system and attank analysis system as single tasks. A more detailed schedule has been developed and will be included in Revision 2 of the engineering task plan. (Revision 1 is HNF-2056, Engineering Task Plan for Development, Fabrication, and Deployment of the Nested, Fixed-Depth Sampling and At-Tank Analysis Systems [Reich and Smalley 1998]). 
HNF-2906 REV 1

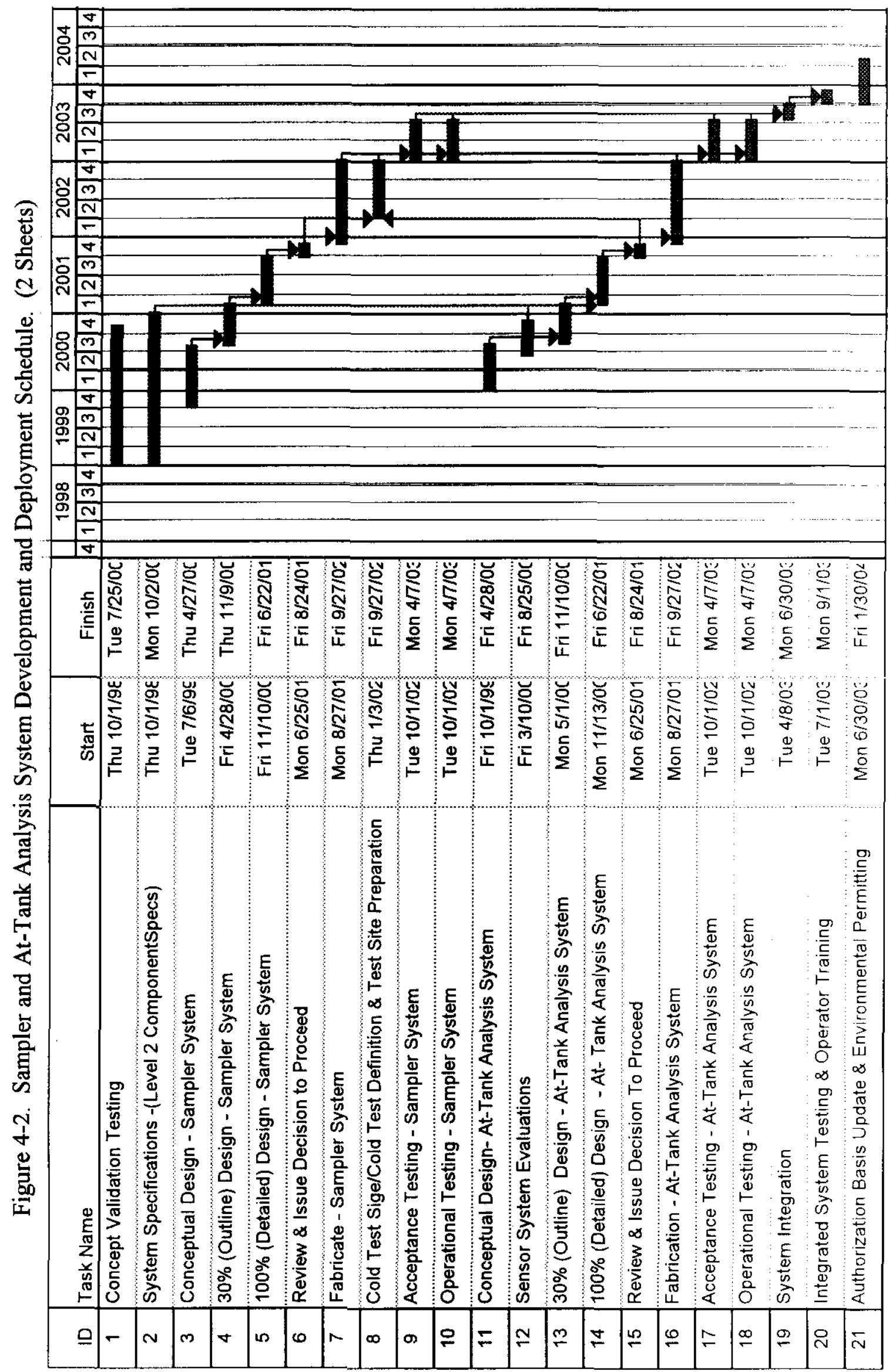




\section{HNF-2906 REV 1}

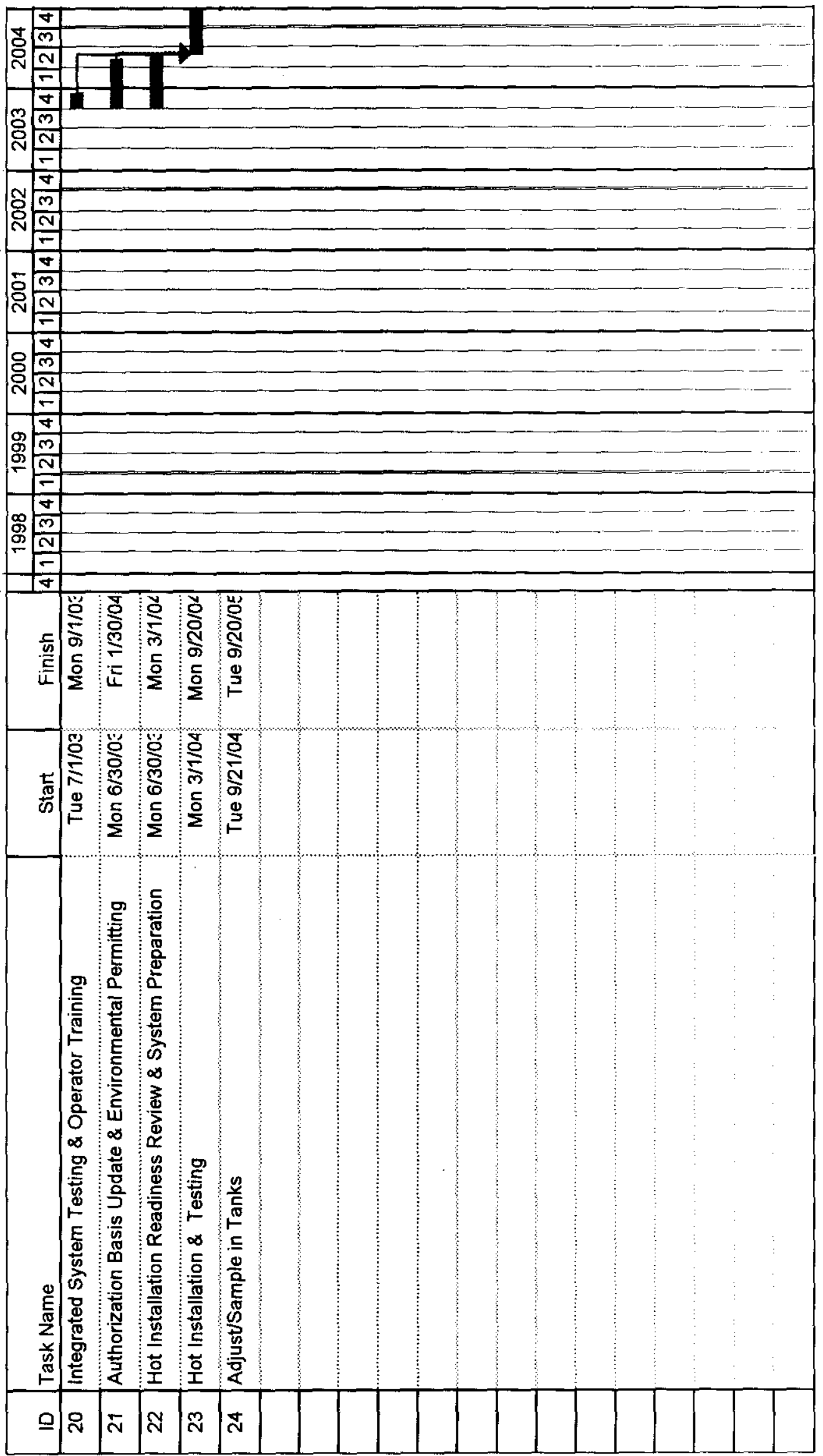




\section{HNF-2906 REV 1}

The sampling system will be designed to be operated independently from the at-tank analysis system. However, the at-tank analysis system will be designed so it cannot operate without the sampler because it uses the waste stream from the power fluidic pump in its sensor loop. The schedule shows that after acceptance and operational cold testing are completed for each system, the systems will be integrated into a single operating system that will be made ready for hot testing in a waste tank. After hot testing is completed, lessons learned from testing will be incorporated into the system as needed. The schedule includes tasks for updating the Site authorization basis as needed and for applying for environmental permits that may be needed in the hot deployment of the sampling and at-tank analysis systems. The sampling and at-tank analysis systems will be ready for deployment in any LAW or HLW feed tank in support of the privatization contract at the end of FY 2004. The schedule assumes that the overall privatization processing schedule is consistent with the baseline schedule contained in the MYWP update guidance for FY 2000 (Erickson 1999).

\subsection{DEVELOPMENT AND DEPLOYMENT COST}

The total cost for providing a prototype mobile, variable-depth sampling system with an at-tank analysis system is estimated as $\mathbf{\$ 8 . 8}$ million. Cost tables are provided in Appendix C. Table C-I shows the cost breakdown by program activity and fiscal year. Table $\mathrm{C}-2$ shows the breakdown of these costs by the EM-30 and EM-50 agency anticipated to be the funding source. This cost estimate includes the following:

- Designing, fabricating, and testing basic system concepts

- Thirty percent (outline) and 100 percent (detailed) design

- Fabricating and cold-testing the prototype system

- Integrating the mobile, variable-depth system with the at-tank analysis system and completing cold testing with the integrated system

- Completing a hot testing campaign with the integrated system in a waste tank.

- Training the operators

- Conducting formal readiness reviews

- Upgrading the authorization basis

- Pursuing environmental permitting.

The estimated cost to produce a duplicate mobile, variable-depth and at-tank analysis system is $\$ 2.1$ million. Table C-3 shows the cost breakdown for this cost estimate.

The cost for continued use and operation of the system would be comparable to that for the deployment of the core sampling truck system. The mobile, variable-depth and at-tank analysis system will be moved from tank to tank, based on the needs defined in the privatization contract. 


\section{HNF-2906 REV 1}

The cost estimate to complete a sampling campaign in a waste tank is approximately $\$ 300,000$ This includes the following activities:

- System setup and in-tank deployment

- Acquisition of approximately 15 samples over the depth of the waste in the tank

- System removal and disposal of in-tank sampling system components

If the system is left inside a waste tank between sampling campaigns, a cost will be incurred to maintain the system in a standby condition where it is ready to use. The cost for maintaining the system inside a tank in a hot readiness state is estimated to be about $\$ 200,000$ per year, based on experience with core trucks. This covers the periodic surveillance and maintenance the system will require.

These estimated costs for the in-tank deployment of the mobile, variable-depth sampling and at-tank analysis systems are consistent with current baseline grab and core sampling system costs. Grab sampling currently costs approximately $\$ 100,000$ to take two waste samples from a tank. Additional grab samples from the same tank riser are estimated to cost $\$ 25,000$ each. To complete a grab sample campaign where samples were taken at 9 different depths, as currently required by ICD-19, Low-Activity Waste Feed, the cost is estimated to be between $\$ 200,000$ and $\$ 300,000$. This cost includes sample acquisition and packaging for shipment in the Hanford Site steel pig transport system.

An additional cost reference point is the cost of a current core sampling campaign. Currently, core sampling using push mode, which is the way the HLW samples would probably be taken, costs about $\$ 300,000$ for a sample from a tank riser. This includes the cost for setup, sampling, and teardown and disposal of contaminated materials. This does not include the amortized cost of maintenance for the core truck system, which adds another estimated $\$ 150,000$ to a tank sampling campaign's cost. The core sampling costs, particularly, are seen to be similar to the costs of taking samples using the mobile, variable-depth sampling system, which also will involve the deployment and disposal of a mast-like structure used inside the tank.

A more detailed cost schedule will be included in Revision 2 of the engineering task plan (Revision 1 is HNF-2056, Engineering Task Plan for Development, Fabrication, and Deployment of the Nested, Fixed-Depth Sampling and At-Tank Analysis Systems [Reich and Smalley 1998].)

\subsection{PROJECT TEAM}

The team that will complete the development and testing of the sampling and at-tank analysis systems includes key staff of the various Hanford Site supporting programs as well as the implementing organizations. The responsibilities are assigned to various companies and organizations as identified in the following paragraphs.

Representatives of the TFA will provide an interface to the TFA Technical Management Team to ensure that the project is implemented in a manner consistent with TFA planning and 


\section{HNF-2906 REV 1}

programmatic goals. Bechtel Babcox and Wilcox Idaho (BB\&W) will provide the technical integration manager (TIM), who will be the point of contact for technical direction of the work scope. The Pacific Northwest National Laboratory will provide the technology delivery manager, who will support the TIM in tracking performance on key deliverables and resolution of technology issues. The individuals in those positions are as follows:

\section{Responsible Technical Integration Manager T. R. Thomas Responsible Technology Delivery Manager B. A. Carteret.}

The CMST Cross Cut Program will provide an interface with the NETL and with the CMST TIM to ensure that the project is implemented in a manner consistent with TFA planning and programmatic goals. The NETL will provide contracting support services to establish and monitor contracts with private contractors who will design, test, and fabricate the at-tank analysis system and design and fabricate the sampler system. The CMST point of contact is as follows:

\section{Responsible Point of Contact \\ G. J. Bastiaans (Ames Laboratory, lowa State University)}

The CHG IPTs group with RPP Planning and Integration will provide program oversight, as well as technical support in review and approval of planning and criteria documentation. The responsible individuals are as follows:
Program Manager
K. A. Gasper
Responsible Engineer
J. N. Appel.

The CHG RPP, Characterization Project will provide technical and funding oversight for this program, as well as support in financial planning and status tracking. The responsible individuals are as follows:
Program Manager/Principal Investigator
R. M. Boger (Numatec Hanford
Corporation)
Responsible Budget Analyst
K. S. Johnson (CHG).

The CHG RPP Characterization Engineering group will provide project oversight and technical leadership and support in the development, review, and approval of design criteria and Site safety and operational documentation. Characterization Engineering also will provide the cognizant engineering and design authority function. The responsible individuals are as follows:
Characterization Engineering
R. M. Boger (Numatec Hanford
Corporation)
Design Authority
G. P. Janicek
Cognizant Manager
J. S. Schofield
Cognizant Engineer
R. G. Brown. 
The CHG RPP Data Assessment and Interpretation group will support the development and approval of criteria and test simulant documentation. The responsible individuals are as follows:

Cognizant Manager

Tank Waste Characterization
J. G. Field (acting manager)

A. M. Templeton.

The CHG RPP also will provide safety, quality, environmental, and operations reviews of documentation as required to support this activity. The responsible individuals are as follows:
Responsible Manager
M. D. Hasty
Safety Engineer
C. D. Jackson
Quality Assurance Engineer
M. L. McElroy
Environmental Engineer
L. L. Penn.

CHG will provide authorization-basis analysis support including unreviewed safety question screenings. The responsible individuals are as follows:
Responsible Manager
C. E. Leach
Responsible Engineer
R. D. Smith

COGEMA Engineering Corporation will provide engineering services for managing the tasks associated with this project and engineering support for the design and test of the prototype sampling and at-tank analysis systems. COGEMA Engineering Company also will prepare documentation (Level 2 specification, engineering task plan, preliminary hazard assessment, etc.) and provide technical coordination for this project. The responsible individuals are as follows:
Responsible Manager
J. L. Smalley
Responsible Engineer
F. R. Reich
Responsible Engineer
G. A. Leshikar
Responsible Engineer
G. W. Wilson.

Pacific Northwest National Laboratory will develop test simulant criteria and review test documentation for the test and validation of the fluidic pumping system components and the sample bottle filling station that will meet RCRA criteria. The responsible individuals are as follows:
Responsible Engineer
M. W. Rinker
Responsible Engineer
M. R. Powell.

Pacific Northwest National Laboratory will support this project through the Robotics Cross Cut Program for the at-tank analysis portion of the overall system. The responsible individuals are as follows:

\author{
Responsible Robotics Program \\ Point of Contact \\ Responsible Engineer
}

\author{
S. A. Bailey \\ R. M. Ozanich (Berkeley Instruments, Inc.)
}




\section{HNF-2906 REV 1}

AEAT, Charlotte, North Carolina, will conduct proof-of-principle testing and design activities for the fluidic pump and RCRA-compatible bottle sample filling systems. The responsible individuals are as follows:

Responsible Point of Contact

Technical Point of Contact
P. Murray

M. Williams. 
HNF-2906 REV 1

This page intentionally left blank. 


\section{HNF-2906 REV 1}

\subsection{RETURN ON INVESTMENT}

The return on investment (ROI) assessment that was included in the Revision 0 Deployment Strategy and Plan was based on waste feed scenarios and assumptions (such as providing LAW feed from 2 to 10 waste tanks, RCRA sampling, etc.) that currently are being modified. The calculations that would provide an ROI for the sampler and at-tank analysis systems have not been updated at this time.

The RPP has assembled a candidate list of risks that were identified while completing the privatization contract requirements. The risks listed in Appendix B are a subset of the RPP risks and are the risks concerned with the limitations and abilities of the baseline core and grab sampling methods to perform within the WFD schedules and budgets established in the privatization contract. Appendix B also contains a qualitative assessment of the risk mitigation that would occur from using the improved sampling and at-tank analysis systems. The improved sampling system with an at-tank analysis system would help mitigate general risk areas by providing the following:

- Flexibility to allow changes in sample volume requirements and sampling sequences within a waste tank for all sizes of LAW or HLW batches

- Capability for at-tank waste measurements that will provide data for supporting process control options that may be needed to meet delivery schedules. Potential situations include failure to properly mix the tank's waste, mixer pump failure, waste that is outside of specifications, a need to blend feeds from two or more tanks, etc.

- Capability to provide samples that meet RCRA criteria for samples with volatile and semivolatile organic constituents

- Shielding and remote handling capability that will allow sampling of waste in a safe manner that may contain higher activity levels than expected without the risk of high operator exposure. The system, including the shipping cask, is being designed for $500 \mathrm{~mL}$ samples of waste with the radiation levels equal to that of the waste in tank AZ-102.

- Capability for deployment in a $30 \mathrm{~cm}$ (12-in.) riser (deployment in a smaller diameter is preferred and will be pursued in the design of the system). The system is mounted on a skid for crane deployment. Therefore, a vehicle access path to the riser will not be needed. The skid also contains the utilities needed to operate the sampling and at-tank analysis system, which eliminates potential problems with tank farm utilities that may not be available.

- Usability in adverse weather conditions where the use of the baseline grab and core sampling methods are restricted. The sampling system is robust, with sealed chambers where sampling, decontamination, and packaging are remotely completed. 


\section{HNF-2906 REV 1}

This page intentionally left blank. 
HNF-2906 REV 1

\subsection{REFERENCES}

AEAT, 1998a, Design, Fabrication \& Demonstration of a Nested Fixed Depth Fluidic Sampler, ESI Document No. 2926-4-001, AEA Technology Engineering Services, Inc., Huntersville, North Carolina.

AEAT, 1998b, Nested Fixed Depth Fluidic Sampler Supplementary Testing, Document No. 2926-4-002, AEA Technology Engineering Services, Inc., Huntersville, North Carolina.

Bailey, S. A., 1998, Technology Task Plan TTP RL37C131, Robotics Tank Waste-1 (PNNL), January 6, 1998, Pacific Northwest National Laboratory, Richland, Washington.

Baldwin, J. H., 1998, Tank Waste Remediation System Retrieval and Disposal Mission Key Enabling Assumptions, HNF-1945, Rev. 1, prepared by Lockheed Martin Hanford Corporation for Fluor Daniel Hanford, Inc., Richland, Washington.

BNFL, 1999, River Protection Project Waste Treatment Plan Interface Control Document ICD-19 between DOE and BNFL Inc. for Low-Activity Waste Feed, BNFL-5139-ID-19, Rev. 4, prepared by BNFL Inc. for the U.S. Department of Energy, Office of River Protection (contract DE-AC06-RL13308), Richland, Washington.

BNFL, 1999, River Protection Project Waste Treatment Plan Interface Control Document ICD-20 between DOE and BNFL Inc. for High-Level Waste Feed, BNFL-5193-ID-20, Rev، 4, prepared by BNFL Inc. for the U.S. Department of Energy, Office of River Protection (contract DE-AC06-RL13308), Richland, Washington.

Boger, R. M., 1999, Interim Fiscal Year 2000 Work Scope for Technical Task Proposal RLO-8-WT-22 to be Funded by Fiscal Year 1999 Carryover Funds, LMHC Correspondence No. 74900-99-018, Lockheed Martin Hanford Company, Richland, Washington.

Claghorn, R. D., J. D. Galbraith, and T. B. Salzano, 1997, Alternatives Generation and Analysis for the Phase I Intermediate Waste Feed Staging System Design Requirements, HNF-SD-TWR-AGA-001, Rev. 1, Lockheed Martin Hanford Corporation for Fluor Daniel Hanford, Inc., Richland, Washington.

Ecology, EPA, and DOE, 1996, Hanford Federal Facility Agreement and Consent Order, Sixth Amendment, February 1996, 89-10, Rev. 4, Washington State Department of Ecology, U.S. Environmental Protection Agency, U.S. Department of Energy, Olympia, Washington. 
Erickson, L., 1999, "Contract No. DE-AC06-96RL13200-Assistant Manager for Waste Processing and Disposal (AMPD) Multi-Year Work Plan (MYWP) Update Guidance for Fiscal Year (FY) 2000," letter \#99-DBD-015, dated August 25, 1999, to R. D. Hanson of Fluor Daniel Hanford, Inc., U.S. Department of Energy, Office of River Protection, Richland, Washington.

Murray, P. B. and M. C. Williams, 1998, Design and Demonstration of a Nested Array of Fluidic Samplers, Project Technical Plan PTP TFA/PF/17/v2, AEA Technology Engineering Services, Inc., Huntersville, North Carolina.

Reich, F. R.., 1999a, Preliminary Level 2 Specification for the Nested, Fixed-Depth Fluidic Sampler, HNF-3483, Revision 1, prepared by COGEMA-Engineering Corporation for Fluor Daniel Hanford, Inc., Richland, Washington.

Reich, F. R.., 1999b, Alternative Generation and Analysis Study for a Waste Sample Container Filling System for the Nested, Fixed-Depth Sampling System, HNF-4545, prepared by COGEMA-Engineering for Fluor Daniel Hanford, Inc., Richland, Washington.

Reich, F. R., 1999c, Phase II Test Plan for the Protection of the Performance of Container Filling Systems, HNF-4883, prepared by COGEMA-Engineering Corporation for Fluor Daniel Hanford, Inc., Richland, Washington.

Reich, F. R., and J. L. Smalley, 1998, Engineering Task Plan for Development, Fabrication, and Deployment of the Nested, Fixed-Depth Sampling and at-Tank Analysis Systems, HNF-2056, prepared by COGEMA-Engineering Corporation for Fluor Daniel Hanford, Inc., Richland, Washington.

RL, 1997, Hanford Science and Technology Needs Statement, 1998, "Representative Sampling and Associated Analysis to Support Operations and Disposal," (Tanks Technology Needs RL-WT09), DOE/RL-98-01, Rev. 0, U.S. Department of Energy, Richland Operations Office, Richland, Washington.

RL, 1998, "Request for Services 1W7P51," with TFA Program Execution Guidance for RL08WT22 (Technology Title: Variable Depth Fluidic Sampling and Analysis), letter to Fluor Daniel Hanford, Inc., dated January 21, 1998, U.S. Department of Energy, Richland Operations Office, Richland, Washington.

Swita, W. R., M. R. Lewis, and M. J. O'Neill, TWRS Retrieval and Disposal Mission Initial Updated Baseline Summary, HNF-1946, Vol. 1, Rev. 1, prepared by Lockheed Martin Hanford Corporation for Fluor Daniel Hanford, Inc., Richland, Washington. 
HNF-2906 REV 1

APPENDIX A

COMPARISION OF OPERATIONAL LOGIC AND SCHEDULES FOR LOW-ACTIVITY WASTE FEED 


\section{HNF-2906 REV 1}

This page intentionally left blank.

A-ii 


\section{APPENDIX A \\ COMPARISION OF OPERATIONAL LOGIC AND SCHEDULES FOR LOW-ACTIVITY WASTE FEED}

\section{A1.0 OPERATION LOGIC USING GRAB SAMPLES AND LABORATORY ANALYSIS (WITHOUT AT-TANK ANALYSIS)}

Figure A-1 shows the operational logic diagram for the existing sampling and analysis approach and for the new sampling and analysis approach. The logic blocks are essentially the same except the samples will not be dip samples and will not be transported to the laboratory unless they are the confirmatory samples. The following sections briefly describe the logic block activities individually.

\section{A1.1 RECEIVE WASTE AND WATER FROM SOURCE TANK (IF APPLICABLE)}

The first half of a double-shell slurry feed (DSSF) waste tank will be decanted and diluted with water as it is transferred from the source tank to the staging (waste feed and staging) tank. The second half of a DSSF waste tank will be diluted, mixed, and settled, then decanted from the source tank to the staging tank.

\section{A1.1.1 Mix Waste in Staging Tank}

The waste is planned to be mixed in the staging tank with one mixer pump for a period of time.

\section{A1.1.2 Take Samples in Staging Tank}

Existing approach: Approximately $100 \mathrm{~mL}$ grab samples of the staging tank will be taken to confirm the tank is well mixed. For planning purposes it is assumed that the samples will be taken at three depths through one riser. Future operational experience and statistical analysis will be used to refine this assumption.

New Approach: Operate the sampling system and obtain tank waste chemical, physical, and radioactivity data from the at-tank analysis system. 
HNF-2906 REV 1

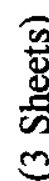

离

先

좀

$\checkmark$

है

$\stackrel{4}{4}$

○

:

일

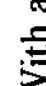

3

:

㺃

考

8

$\frac{1}{4}$

岂

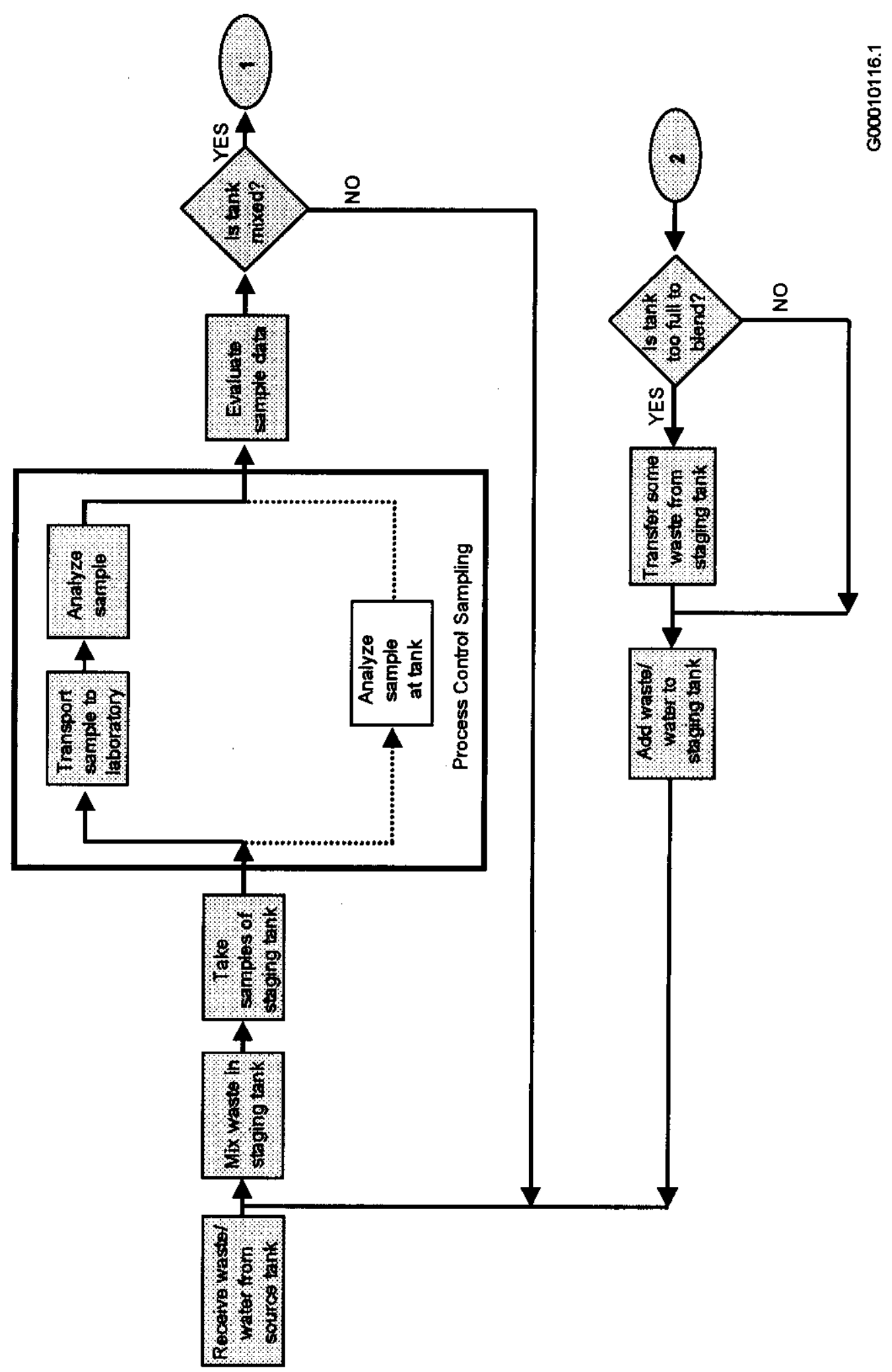


HNF-2906 REV 1

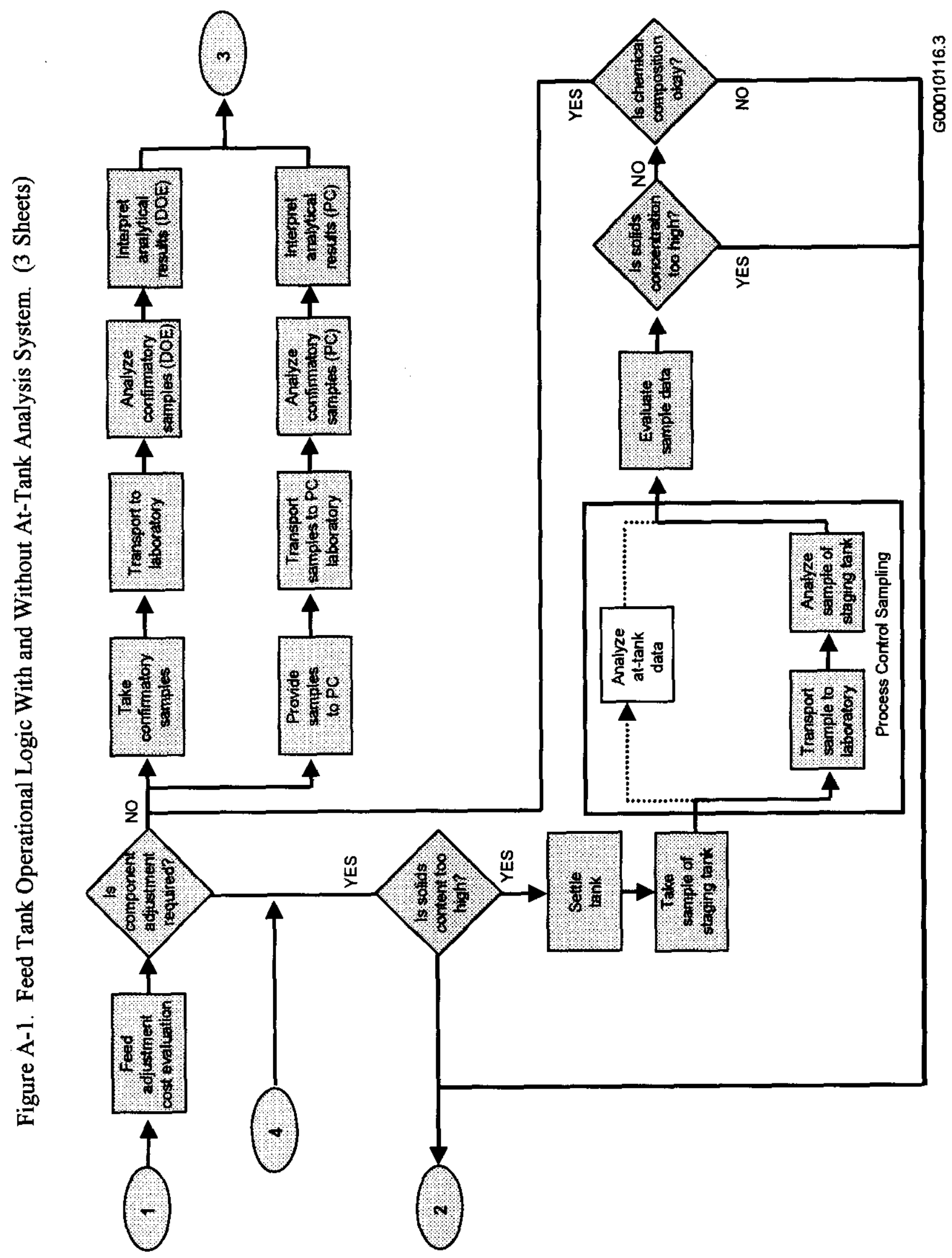




\section{HNF-2906 REV 1}

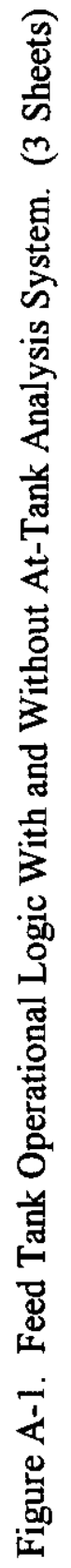




\section{HNF-2906 REV 1}

\section{A1.1.3 Transport Samples}

Existing approach: The samples will be placed in shielding pigs and transported to the laboratory via truck.

New approach: This step is not needed.

\section{A1.1.4 Analyze Sample}

Existing approach: The samples will be removed from the shielding pigs, prepared as required, and analyzed. For planning purposes it is assumed that the analyses include inductively coupled plasma spectrometer (ICP) analysis of the filtrate, bulk density, pH, and percent solids. Future operational experience and contract negotiations will be used to refine this assumption.

New approach: This step is not needed.

\section{A1.1.5 Evaluate Sample Data}

Existing approach: This evaluation will be done to determine if most of the soluble solids have dissolved, the tank is well mixed, and the combined feed is likely to be within specification.

New approach: Analyze the at-tank analysis system sensor data to determine if most of the soluble solids have dissolved, the tank is well mixed, and the feed is likely to be within specification.

\section{A1.1.6 Feed Adjust Cost Evaluation}

If the feed is not likely to be within specification, a cost evaluation will be performed. This will compare the cost of adjusting the feed for various adjustment scenarios, blending the feed, or potentially accepting an increased payment to the privatization contractors based on some formula negotiated in the contract.

\section{A1.1.7 Take Confirmatory Samples}

If the composition is not likely to require adjustment or adjusting or blending is not cost effective, samples will be taken to confirm that the composition is acceptable. The number of grab samples from each tank will range from 3 to 19 , depending on the feed batch. The proposed number of samples for each batch is given in the Alternative Generation and Analysis for the Phase 1 Intermediate Waste Feed Staging System Design Requirements, HNF-SD-TWR-AGA-001, Rev.1 (Claghorn et al. 1997). The U.S. Department of Energy (DOE) will develop further details of feed qualification sampling requirements. The requirements will be included in the contract. 


\section{HNF-2906 REV 1}

\section{A1.1.8 Transport to Laboratory}

The confirmatory samples will be placed in casks and transported to the DOE laboratory (assumed to be the 222-S Laboratory) via truck.

\section{A1.1.9 Analyze Confirmatory Samples (DOE)}

The samples will be removed from the casks, prepared as required, and analyzed. The proposed analyses are listed in Alternatives Generation and Analysis for the Phase 1 Intermediate Waste Feed Staging System Design Requirements, HNF-SD-TWR-AGA-001 Rev.1 (Claghorn et al. 1997). These will be revised as needed based on revisions to the contracts with the privatization contractors.

\section{A1.1.10 Interpret Analytical Results (DOE)}

The sample results will be compared against the envelope specifications contained in the contract.

\section{A1.1.11 Provide Samples to the Privatization Contractors}

A $1 \mathrm{~L}$ sample will be provided to the privatization contractors for analysis to confirm the feed composition.

\section{A1.1.12 Transport Samples to the Privatization Contractors' Laboratory}

The confirmatory samples will be placed in casks and transported to the privatization contractors' laboratory via a method chosen by the privatization contractor.

\section{A1.1.13 Analyze Confirmatory Samples (Privatization Contractors)}

If the privatization contractors choose, the samples will be removed from the casks, prepared as required, and analyzed. The proposed analyses will consist of whatever the privatization contractors choose.

\section{A1.1.14 Interpret Analytical Results (Privatization Contractor)}

If the privatization contractors choose, the sample results will be compared against the envelope specifications. 


\section{HNF-2906 REV 1}

\section{A1.1.15 Resolve Dispute/Agree on Results}

If a dispute over the analytical results occurs, the dispute resolution procedure contained in the contract will be followed.

\section{A1.1.16 Prepare Feed Qualification Report}

A feed qualification report will be prepared in accordance with the privatization contract.

\section{A1.1.17 Provide Feed Qualification Report to Privatization Contractor}

This activity is the official transmittal of the feed data to the privatization contractor.

\section{A1.1.18 Transfer Waste to Privatization Contractors}

The waste will be transferred to the privatization contractor's feed tanks via a pipeline.

\section{A1.1.19 Transfer Waste from Staging Tanks}

If the staging tank requires some adjustment and is too full of waste to blend or add chemicals, some or all of the waste will be transferred from the staging tank back to a tank in the tank farms. Which tank receives the waste will depend on the amount and the composition of the waste in the staging tank and in the receiving tank.

\section{A1.1.20 Add Waste/NaOH to Staging Tanks}

The staging waste will be blended by transferring waste from a source tank to the staging tank. Water or chemicals will be added as necessary to meet the feed specification.

\section{A1.1.21 Settle Waste}

If required, the waste in the staging tank will be settled to reduce the solids concentration in the liquid.

\section{A2.0 COMPARISON OF OPERATING SCHEDULES}

To demonstrate the potential time savings associated with using the mobile, variable-depth fluidic sampler and at-tank analysis method over the grab sample and 222-S Laboratory analysis method, a schedule was prepared for an assumed path through the logic. Figures A-2 and A-3 show the assumed logic path for grab sampling and mobile, variable-depth sampling, 
respectively. The tank is mixed, then sampled and found to be inadequately mixed and so is mixed and sampled again. After the second mixing period, the solids content appears to be too high; therefore, the tank is allowed to settle. After allowing the tank about two weeks to settle, a sample is taken and the solids concentration is still too high. Chemicals are added to reduce the solids concentration. The tank is mixed and sampled again. Both the chemical and physical specifications are met and the confirmatory samples are taken. The analysis of the confirmatory samples agrees with the preliminary indication; the feed qualification report is prepared and the feed is transferred.

The schedule using the grab sample and 222-S Laboratory is shown in Figure A-2. Each time samples are taken, transporting the samples to the 222-S Laboratory takes about 1 day. Preliminary analyses are assumed to take about 14 days. (The laboratory staff are working now to identify technical approaches for shortening this time.) The confirmatory analyses takes about 60 days. The estimated time to complete this process is 186 days. If bad weather caused any delays, the schedule would be correspondingly longer.

The schedule using the mobile, variable-depth fluidic sampler and at-tank analysis is shown in Figure A-3. For this schedule, the preliminary analyses that check mixing (analyzing for a simple chemical constituent such as sodium) or settling (measuring percent solids) are assumed to be completed the same day the sample is taken. For preliminary analyses after chemical adjustment, the samples are assumed to require an ICP analysis and, therefore, would be transported to the 222-S Laboratory (taking about 1 day) and analyzed (taking about 14 days). Again the confirmatory analyses require about 60 days. The estimated time to complete the process using the mobile, variable-depth sampler is 141 days, or about 45 days less than the process using grab samples. Bad weather is unlikely to cause any lengthening of this schedule. 


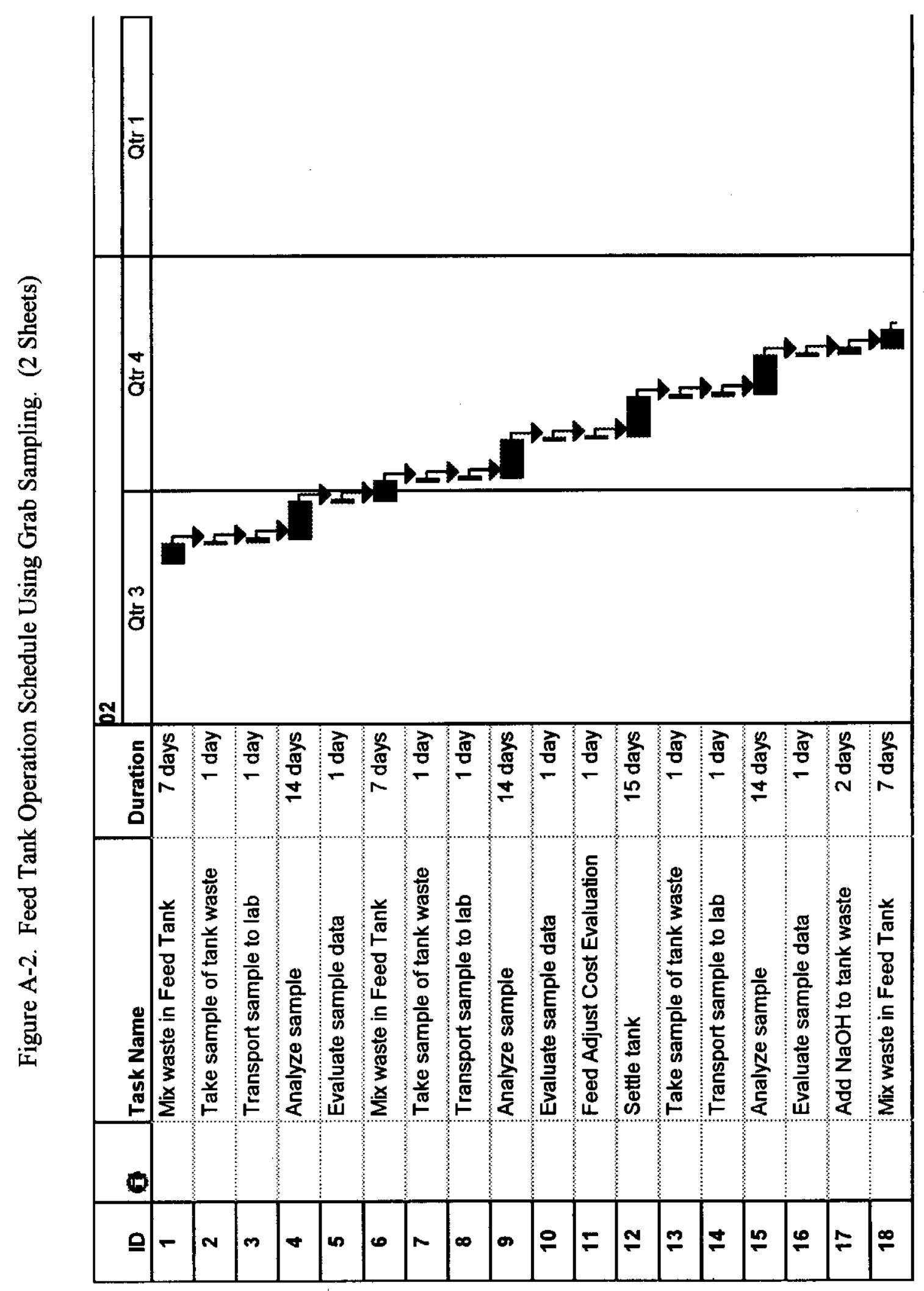




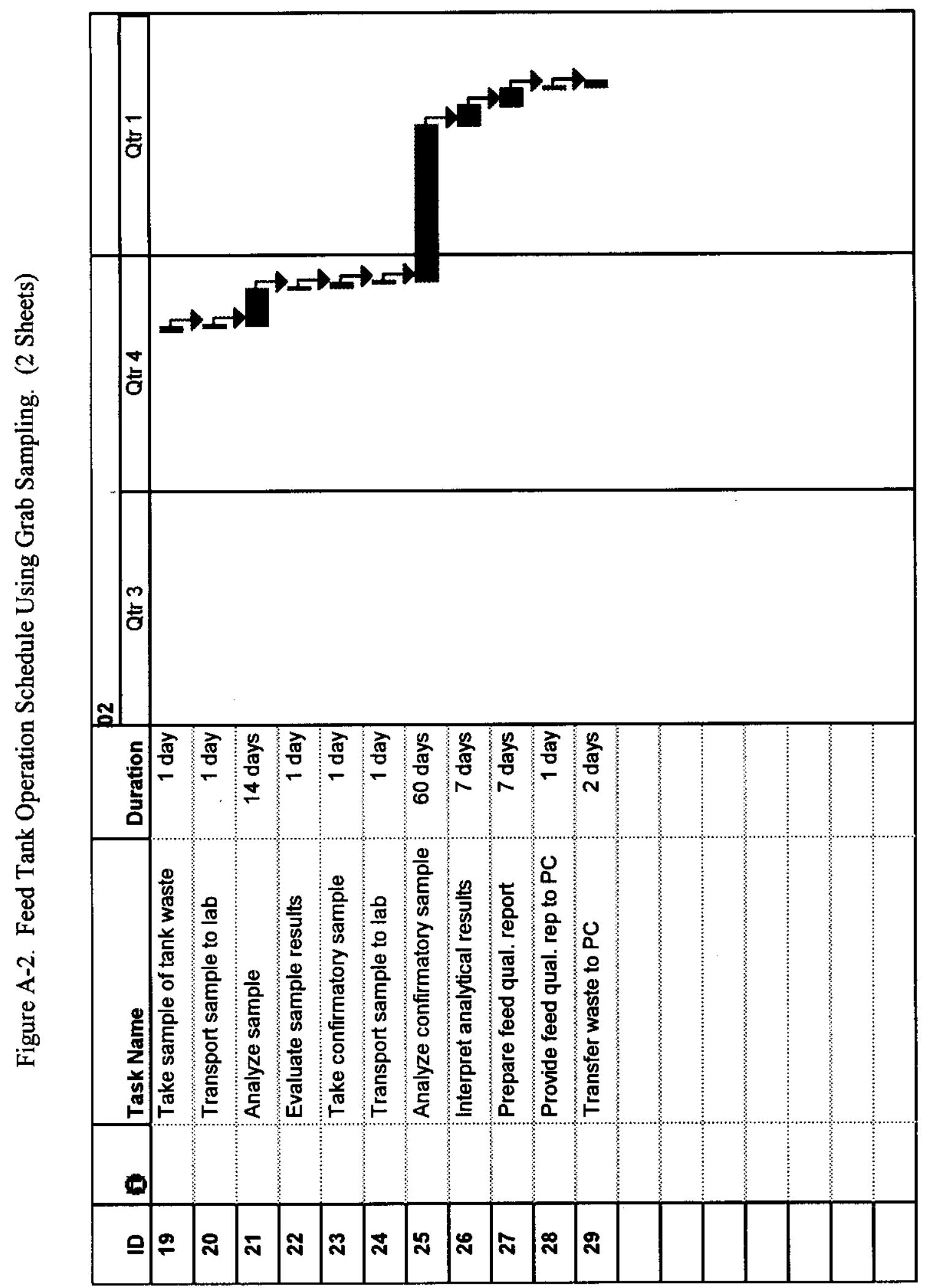


HNF-2906 REV 1

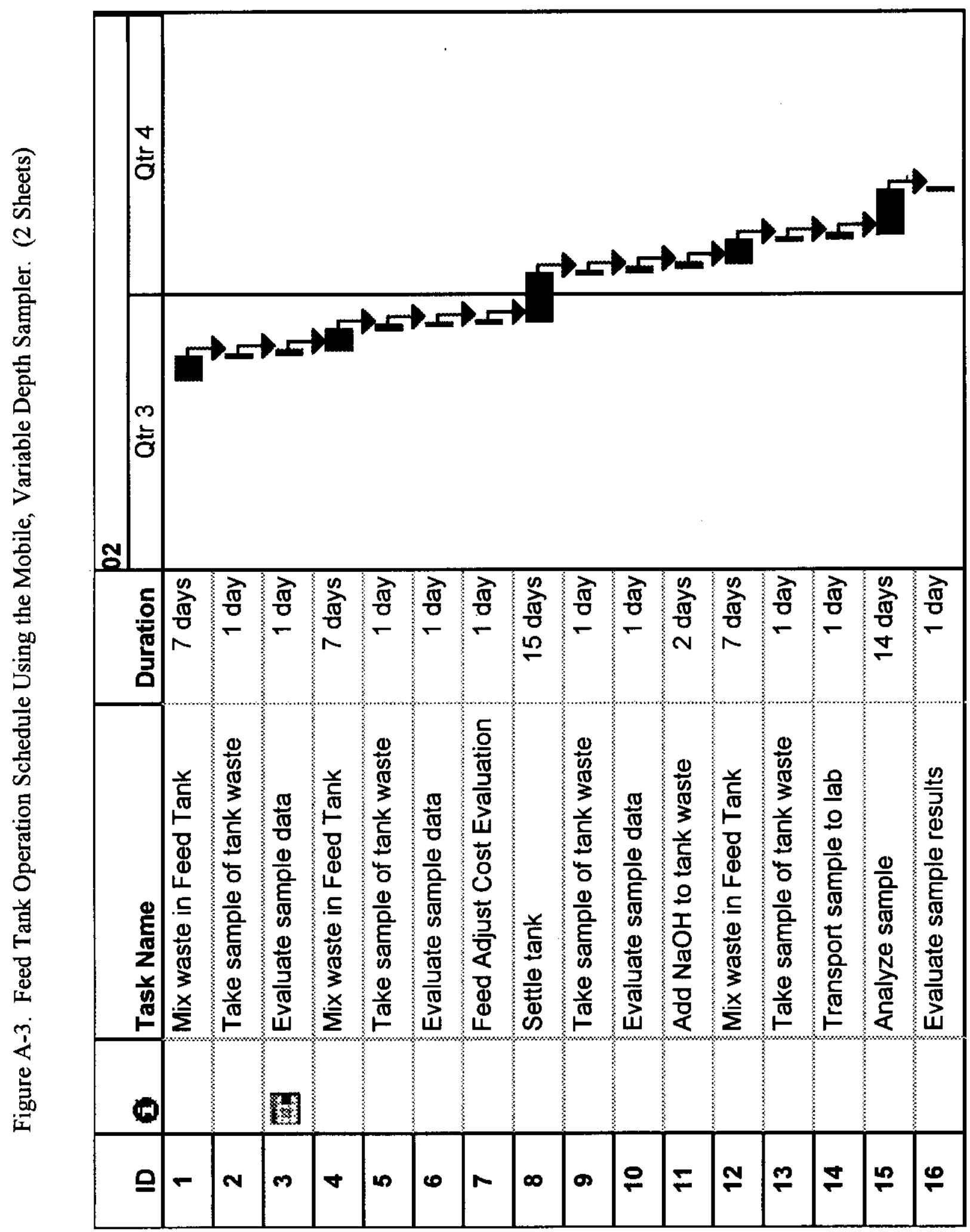




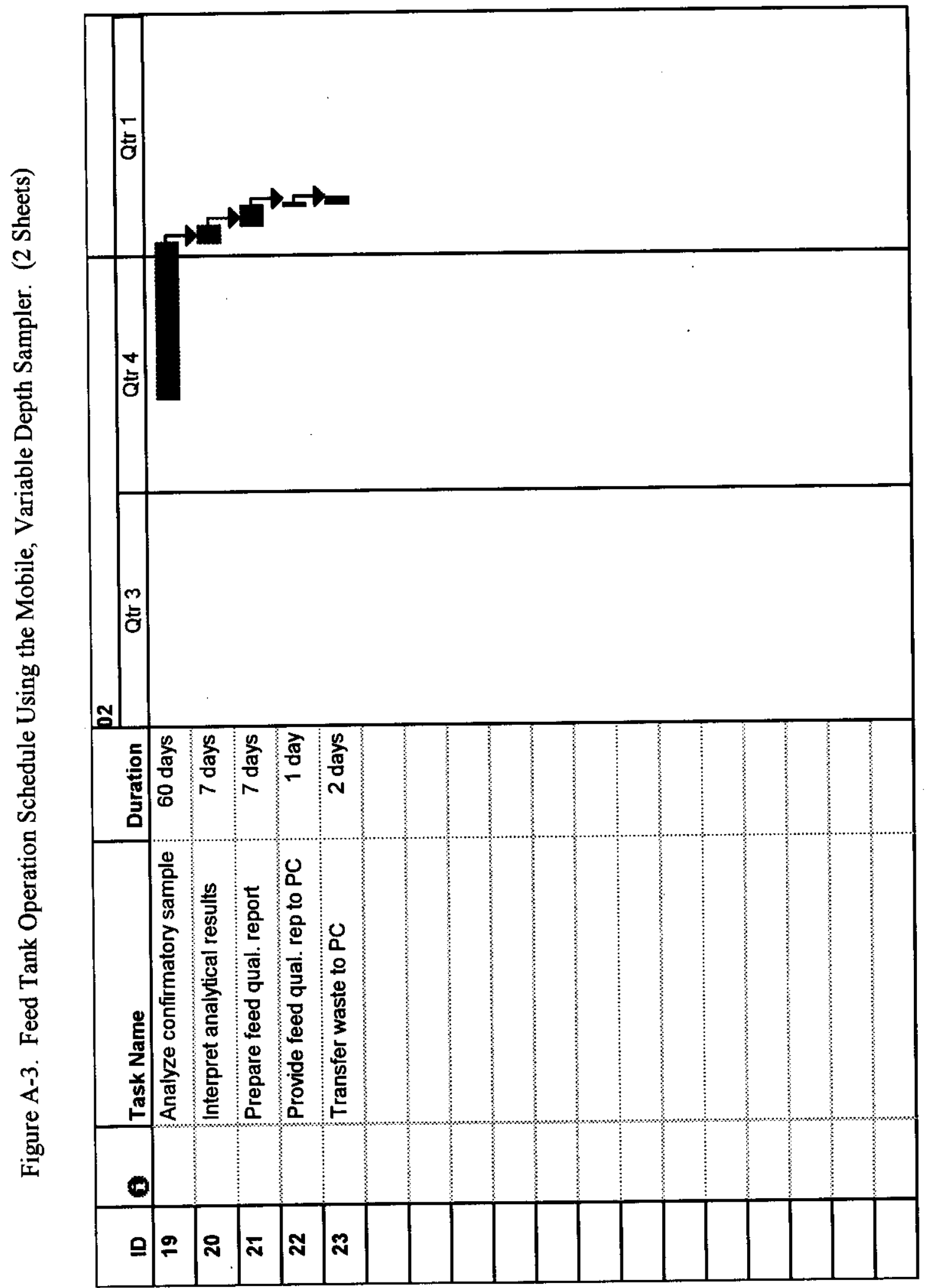




\section{HNF-2906 REV 1}

\section{APPENDIX B}

\section{OPERATING SCENARIO RISK ANALYSIS}


HNF-2906 REV 1

This page intentionally left blank.

B-ii 
HNF-2906 REV 1

\section{APPENDIX B}

\section{OPERATING SCENARIO RISK ANALYSIS}

\section{B1.0 INTRODUCTION}

The River Protection Project (RPP) has identified a list of risks associated with the implementation and completion of the privatization contract. (The risk data were obtained from interviews with Site experts. The risk data are being used as input for Site planning and budgeting.) This list includes risks pertaining to the limitations and abilities of the baseline core and grab sampling system performance and their abilities to perform within waste feed delivery (WFD) schedules and budgets established for supporting the privatization contract.

The risks described in Section B2.0 and B3.0 are a subset of the total RPP Candidate Risk List. These are the risks that would be mitigated with developing and deploying the mobile, variabledepth sampling system with an at-tank analysis system. The risk list is segregated into two groups, critical and noncritical risks, following the format of the RPP Candidate Risk List.

\section{B2.0 CRITICAL RISKS}

\section{B2.1 CR-025 DEFINITION OF WASTE CERTIFICATION STRATEGY}

\section{B2.1.1 Risk Statement}

CR-025 -If the RPP analytical waste certification strategy for both low-activity waste (LAW) and high-level waste (HLW) is not defined and approved by the U.S. Department of Energy (DOE), large quantities of feed may be rejected and feed transfers may be delayed for substantial periods while DOE and the privatization contractor reconcile the analytical results.

\section{B2.1.2 Discussion}

This risk is twofold. First, the schedule to stage the LAW feed will accelerate as a result of the need to adjust the feed batch more than once. Second, the analytical results may not be available in time to meet schedules. If DOE finds out too late that the composition is not within specification, the schedule may not allow time to make adjustments without either invoking an idle-facilities penalty or paying some compensation to BNFL Inc. (BNFL) for processing offspecification feed. 


\section{HNF-2906 REV 1}

\section{B2.1.3 Sampler and At-Tank Analysis System Mitigation Actions}

The at-tank analysis system will provide on-line, real-time data for assessing the homogeneity of the waste batch. This will reduce the risk of mixing a waste batch either inadequately or longer than necessary. A variable-depth sampler can obtain large volumes of waste samples within a short time. This will reduce the sampling time needed when the at-tank analysis system data indicate that a steady-state and/or homogeneous condition exists in the tank. The sampling and at-tank analysis systems can operate while the tank mixer pumps are operating and can provide waste samples that are representative of the waste batch. This will reduce the time to bring a tank batch to an acceptable status and allow the status of a waste batch to be monitored until acceptable conditions are observed in the data from the at-tank analysis system.

\section{B2.2 CR-047 MLXER PUMPS}

\section{B2.2.1 Risk Statement}

CR-047 - If mixer pump technology is not sufficiently effective or efficient, CH2M Hill Hanford Group, Inc. (CHG), may not be able to deliver sufficient HLW feed to BNFL.

\section{B2.2.2 Discussion}

The risk is that the tank mixer pumps may fail or fail to properly mix a tank waste batch within a reasonable time. This may require extending the WFD schedule to accommodate additional time for mixing and may require invoking an idle-facilities penalty. A failed mixer pump will prevent the waste within a tank from being thoroughly mixed before the time for sampling and transfer. This may result in the transfer of waste that is not within specification and is not represented by the waste batch samples.

\section{B2.2.3 Sampler and At-Tank Analysis System Mitigation Actions}

By using a variable-depth sampler with an at-tank analysis system, the mixing (steady-state and perhaps homogenous) status of a tank waste batch can be quickly assessed. Repeated assessments can provide data on the mixer pumps' progress with the tank waste without shutting down the mixer pumps. This will allow a timely decision-making process to be used to identify a path forward for the waste batch, including continued mixing, blending, and decanting options, or transfer. In addition, when the in-tank data show an acceptable waste condition, waste batch validation samples can be acquired quickly with the sampling system and shipped to the laboratory for validation measurements. The sampling system with the at-tank analysis system, which can operate while the mixer pumps are operating, will reduce errors that may result from samples not being representative of a waste batch, as well as provide a means to manage the waste tank before sampling and transfer to BNFL. The baseline grab and core sampling systems do not have any capabilities for taking at-tank waste measurements. 


\section{B2.3 CR-050 POTENTIAL FOR REJECTED FEED}

\section{B2.3.1 Risk Statement}

CR-50 - If a feed batch does not fit within BNFL's operating, permit, and safety basis limits, it may be rejected.

\section{B2.3.2 Discussion}

The risk is that waste feed may not meet Phase I specifications and will require unplanned adjustments that will, in turn, require unplanned sampling. These unplanned adjustments will decrease the feed staging rate and could cause DOE to pay penalties to BNFL for idle facilities, and potentially require multiple sampling and analysis campaigns that are outside the planned schedule. Additional costs for sampling and analysis will be incurred, along with the potential for idle facilities penalties.

\section{B2.3.3 Sampler and At-Tank Analysis System Mitigation Actions}

The variable-depth sampler with an at-tank analysis system will allow the mixing (homogeneity) status of a tank waste batch to be quickly assessed without shutting down the mixer pumps to take samples, as is required with the baseline grab and core sampling methods. Samples will not need to be taken and analyzed to assess the homogeneity of a tank waste batch. When the intank data show an acceptable waste condition, waste batch validation samples can be acquired quickly with the sampling system and shipped to the laboratory for validation measurements. The sampling system with the at-tank analysis system will reduce errors that could result from analyzing samples that are not representative of a waste batch, as well as provide a means to manage the waste tank before sampling and transfer to BNFL. The sampling system can operate when the tank mixer pumps are operating, can sample waste at any depth for any batch size, and will provide samples that are representative of the materials in a waste batch.

\section{B2.4 CR-062 DESIGNATION OF POLY- CHLORINATED BIPHENYLS IN TANK WASTE (TSCA REGULATED)}

\section{B2.4.1 Risk Statement}

CR-062 - If the status of polychlorinated biphenyls (PCB) for the tank waste changes, new requirements for permitting, equipment, and operations will result in increased cost and schedule challenges. 


\section{B2.4.2 Discussion}

The risk is that, currently, the baseline grab and core sampling systems cannot take samples that meet all the Resource Conservation and Recovery Act of 1976 (RCRA) criteria for samples containing volatile and semivolatile organic constituents. An analysis must be completed to identify the issues in upgrading these baseline methods. The schedule could be affected if significant development, test, and verification testing are required to upgrade the baseline system to provide samples that meet RCRA criteria.

\section{B2.4.3 Sampler and At-Tank Analysis System Mitigation Actions}

The mobile, variable-depth sampling system provides samples in $500 \mathrm{~mL}$ bottles that meet RCRA criteria for materials containing volatile and semivolatile organic constituents. The system fills the sample bottles without pulling a vacuum on the waste (vacuum will affect the volatile and semivolatile contents), seals the bottles, and fills each bottle so the bottle contains no visible headspace, as required by RCRA.

\section{B3.0 NON-CRITICAL RISKS}

\section{B3.1 DQO REVISIONS}

This risk event is identified in the following:

- 100.ANA-1 - Waste Feed Delivery Program Candidate Risk List

- 100.BNF-1, 100.COR-1, and 100.GRB-1 - Characterization Support Risk Management List

\section{B3.1.1 Risk Statements}

- 100.ANA-1 -Revisions to the referenced DQO may significantly change the scope of the sample or laboratory analysis required.

- $\quad$ 100.BNF-1 - Revisions to the referenced DQO may significantly change the sample size. Likelihood- high: consequence-medium, risk value- medium.

- 100.COR-1 - Revisions to the referenced DQO may significantly change the scope of the sample or laboratory analysis required. Likelihood- medium, consequence-medium, risk value- medium.

- 100. GRB-1 - Revisions to the referenced DQO may significantly change the scope of the sample or laboratory analysis required. Likelihood- medium, consequence-medium, risk value- medium 


\section{HNF-2906 REV 1}

\section{B3.1.2 Discussion}

The risk is that the revised DQO may require larger sample volumes and more representative samples from within a waste batch. Obtaining representative samples over the full depth of small waste batches will be difficult using the baseline core and grab sampling methods. The HLW batches will range from $200,000 \mathrm{~L}$ to $600,000 \mathrm{~L}$. A $200,000 \mathrm{~L}$ batch occupies a $46 \mathrm{~cm}$ (1.5-ft) depth in a $23 \mathrm{~m}(75-\mathrm{ft})$-diameter waste tank while a $600,000 \mathrm{~L}$ batch will be in a $1.5 \mathrm{~m}$ (5-ft)-thick layer. These waste batches will be located at any depth in a full or partly full waste tank. Collecting multiple samples within the shallow-depth waste batches will be extremely difficult using core sampling that takes $61 \mathrm{~cm}$ (2-ft) core samples. The lack of precise depth control with grab sampling also will make acquiring multiple samples within this shallow-depth waste difficult.

Larger volumes of sample will affect sampling schedules and increase the operator exposure with the baseline sampling methods. The additional operational changes and measures required to accommodate the higher activity samples will increase sampling time.

The DQO changes may include the need to meet RCRA criteria for volatile and semivolatile organics that the current grab and core sampling methods cannot meet.

\section{B3.1.3 Sampler and At-Tank Analysis System Mitigation Actions}

The mobile, variable-depth sampling system can rapidly fill $500 \mathrm{~mL}$ sample bottles from any waste depth in a tank. This will allow for a large number of representative waste samples. The sampler's in-tank deployment system provides precise control of the depth at which a sample is drawn. This precise control allows multiple samples to be obtained from even the smallest waste batch at any depth in a waste tank.

The sampler system is designed for remote handling of its $500 \mathrm{~mL}$-bottle samples with shielding that will protect operators from high-dose-rate samples. The $500 \mathrm{~mL}$ sample containers will be remotely packaged and placed in the Hanford Site Steel Pig package for shipment.

Each sample bottle filled by the mobile, variable-depth sampling system will meet the RCRA criteria for materials containing volatile and semivolatile organic constituents. The system will provide sealed sample bottles without pulling a vacuum on the waste (vacuum affects the volatile and semivolatile contents), and will fill the bottles so they contain no visible (zero) headspace, as required by RCRA.

The sampling system is flexible and can be deployed in any waste tank with an open $30 \mathrm{~cm}$ (12-in.) riser (the design preference is for a system that can fit into a $15 \mathrm{~cm}$ [6-in.] riser). The sampling system can sample while the mixer pumps are operating and, using the waste mixing and settling status data from the at-tank analysis system, can provide samples when the sample batch conditions are optimum. 


\section{HNF-2906 REV 1}

\section{B3.2 SAMPLE SIZE}

This risk is identified in ANA-8 - Waste Feed Delivery Program Candidate List

\section{B3.2.1 Risk Statement}

100.ANA-8 - Sample size is limited in some cases, which may restrict analytical protocols Waste Feed Delivery Program Candidate List

\section{B3.2.2 Discussion}

The risk is that, using the baseline grab and core sampling methods, larger sample volumes will increase the time required to obtain waste samples, thus increasing the exposure for the operators. Although grab sampling can fill $500 \mathrm{~mL}$ sample bottles, operator exposure will increase during the sampling process from the higher activity $\mathrm{HLW}$ tanks. The core sampling system currently is limited to $350 \mathrm{~mL}$ samples per core segment. Development work would be required to increase this sample volume capacity and to accommodate the increased dose rate expected with the higher activity HLW tanks. Alternatively, two core segments may be taken at each elevation to get the required volume.

\section{B3.2.3 Sampler and At-Tank Analysis System Mitigation Actions}

The mobile, variable-depth sampling system is flexible and can rapidly fill $500 \mathrm{~mL}$ sample bottles from any waste depth in a tank. The sampler system is designed for remote handling of its $500 \mathrm{~mL}$ bottle samples with built-in shielding to protect operators from high-dose-rate samples. All sampling and packaging operations are remote, including the bagging and insertion of the sample into the Hanford Site Steel Pig. The Steel Pig is currently capable of handling a $500 \mathrm{~mL}$ waste sample from the most hazardous HLW material (tank 241-AZ-102).

\section{B3.3 RISER ACCESS}

This risk event is identified in 100.COR-8 - Waste Feed Delivery Program Candidate Risk List.

\section{B3.3.1 Risk Statement}

100.COR-8 - Access to the riser may be unusual and require significant extra preparations. These preparations may include the need to construct an access ramp for the core sampling truck.

\section{B3.3.2 Discussion}

The risk is that some of the waste tanks may require unusual and significant extra preparations. Depending on site configuration, these could include constructing an access ramp to install the 
core truck sampling system. These unplanned preparations will lengthen the WFD schedule and increase the cost for sampling.

\section{B3.3.3 Sampler and At-Tank Analysis System Mitigation Actions}

The mobile, variable-depth sampling system is mounted on a skid deployed by a crane. The attank preparation to support a skid-mounted system is less than that required for a truck-mounted system.

\section{B3.4 INSUFFICIENT CHARACTERIZATION SAMPLING AND ANALYSIS CAPACITY}

This risk event is identified in list 130.B80-3 - Waste Feed Delivery Program Candidate Risk List and Retrieval Operations Engineering Risk Management List

\section{B3.4.1 Risk Statement}

130.B90-3 - The characterization sampling and analysis system cannot meet the estimated capacity required for combined WFD and non-WFD operations

\section{B3.4.2 Discussion}

The risk is that the current baseline sampling methods cannot meet the estimated capacity required for combined WFD and non-WFD operations. The baseline sampling systems were designed to meet the schedule and needs of the non-WFD characterization work scope and will be needed for ongoing work scope that overlaps with the startup of the privatization schedule. This will result in schedule delays and increased costs for both WFD and non-WFD sampling operations, with the risk of idle facility penalties for WFD.

\section{B3.4.3 Sampler and At-Tank Analysis Systems Mitigation Actions}

The sampler system (or systems) will be dedicated to supporting the sampling needs for the privatization contract while the core sampling trucks and grab sampling crews can continue to support the non-WFD needs. In addition, the mobile, variable-depth sampling system is flexible and can rapidly fill $500 \mathrm{~mL}$ sample bottles from any waste depth in a tank. This allows large volumes of waste samples to be obtained quickly.

The waste property data, which can be used to assess waste batch mixing/settling (homogeneity) status, will allow samples to be obtained at optimum mixing and settling conditions without the need to obtain and ship samples to the 222-S Laboratory for interim analysis. Using these data for operational control will further increase the schedule and cost efficiency of the WFD sampling and analysis operations. 
HNF-2906 REV 1

\section{B3.5 WEATHER}

This risk event is identified in 100.COR-4 and 100.GRB-4 - Characterization Support Risk Management List

\section{B3.5.1 Risk Statement}

- 100. COR-4 - Weather conditions may require additional duration for sampling.

- 100.GRB-4 - Weather conditions may require additional duration for sampling. Likelihood - high; Consequence - medium; Risk value - medium.

\section{B3.5.2 Discussion}

The risk is that the susceptibility of the baseline grab and core sampling methods to inclement weather conditions, including severe cold, heavy moisture, and wind, will extend the time needed to complete sampling campaigns.

\section{B3.5.3 Sampler and At-Tank Analysis System Mitigation Actions}

The mobile, variable-depth sampling system will be capable of operating in more severe weather than the current baseline grab and core sampling systems. The sample filling, packaging, and handling operations are completed in sealed chambers as remote operations. The system has temperature control for critical waste- and wash-water-contacting components that will allow operation in subfreezing conditions. The sampling system's chambers provide shielding and containment for the radioactive materials. The three-chamber design, with sealed doorways between chambers, water flushing of waste-contacting surfaces, and high-efficiency particulate air (HEPA)-filtered air control, ensures containment and control of radioactive waste materials.

\section{B3.6 HIGH ACTIVITY WASTE SAMPLES AND TANKS}

This risk event is identified in the following:

- 130.B45-2, 160.A14-2, 100.BNF-2, 100.COR-2, and 100.GRB-2-Characterization Support Risk Management List

- 110.070-3 - Sampling - Operations Support Risk Management List.

\section{B3.6.1 Risk Statements}

- 130.B45-2 and 160.A14-2 - If samples larger than $1 \mathrm{~L}$ are required in a short period (i.e., the core sampling trucks cannot be used) from the HLW tanks, new sampling methods 


\section{HNF-2906 REV 1}

may be required to make obtaining large volumes more efficient and reduce personnel exposure to radiation. This may require developing new shipping casks and hot cell facilities to receive the new casks.

- 100.BNF-2, 100.COR-2, and 100.GRB-2 - The tank may contain higher activity levels than expected, and may require additional radiological controls to reduce operator exposure during sample transport to the laboratory. Likelihood - low; Consequence low; Risk value - low.

- Samples may be more radioactive than expected as a result of sludge mixing from the mixer pump operation. This could require redesign of the sampling shielding or transportation cask, which would interrupt the sampling process, resulting in significant delay and cost increase.

\section{B3.6.2 Discussion}

The risk is that the tank waste may have a higher activity than expected, which will increase operator dose rates and require additional radiological controls. Higher operator exposures will require additional caution, planning, and procedures for some waste. This, in turn, will increase the time needed to complete sampling and will increase sampling costs. Updating and relicensing a new shipping cask is likely to take several years. The need to develop new equipment and procedures also will affect cost and schedule. The need to implement unplanned procedures will extend the WFD schedule and increase the cost of obtaining the waste batch validation samples as required by the privatization contract.

\section{B3.6.3 Sampler and At-Tank Analysis System Mitigation Actions}

The mobile, variable depth sampling system is flexible and can rapidly fill $500 \mathrm{~mL}$ sample bottles from any waste depth in a tank. All the mobile, variable-depth sampling system's operations are completed in sealed chambers that have radioactive shielding and are sealed to contain and control the radioactivity. The system uses HEPA filters and will be operated at a slight vacuum to control airborne materials. Remote manipulators will be used to bag-out the $500 \mathrm{~mL}$ sample bottles and insert them into the Steel Pig containers. Currently, a $500 \mathrm{~mL}$ waste sample from the most hazardous HLW material (tank 241-AZ-102) can be shipped on Site using the Steel Pig.

The sampling system chambers have built-in water flushing systems to minimize contamination in the sampling system and will be used to clean the surface of sample bottles after filling and capping operations are completed.

The at-tank analysis system on the sampling system will provide waste property data from which the waste batch mixing and settling (homogeneity) status can be assessed. Using these data for operational control will allow samples to be obtained at optimum mixing and settling conditions without the need to obtain and ship samples to the 222-S Laboratory for analysis. This will 


\section{HNF-2906 REV 1}

improve the efficiency of the sampling campaigns, which will reduce the operator exposure required to support the privatization contract sampling tasks.

\section{B3.7 MIXER PUMPS}

This risk event is identified in the following:

- $\quad 110.070 .1$ - “Test Duration” - Operations Support Risk Management List

- $\quad 110.070 .2$ - "Pump Failure” - Operations Support Risk Management List

- 110.075 .2 - "Mixer Pump Failure" - Operations Support Risk Management List.

\section{B3.7.1 Risk Statements}

- 110.070-1 - The mixer pump might have to be run longer to achieve mobilization goals or operation might need to be cut short because of temperature limitations.

- 110.070-2 - The mixer pump might fail to operate. Funding has not been included for removal and replacement of failed mixer pumps.

- 110.075-2 - The mixer pumps might fail to operate. The mixer pumps were installed in June 1996 and the shafts have been rotated by hand until present.

\section{B3.7.2 Discussion}

The risk is that the failure of a mixer pump or the failure for a tank to be mixed will extend the WFD schedule and require changes in how waste batches being prepared for transfer to BNFL are managed, which will affect delivery schedule and cost. This scenario carries the risk of a potential idle facility penalty.

The baseline core or grab sampling with sample analysis in the 222-S Laboratory cannot provide real-time waste data for operational control and management of waste batches. The absence of in-tank data measurement capabilities means that samples must be extracted and sent to the 222-S Laboratory for interim analysis of the status of a waste batch.

\section{B3.7.3 Sampler and At-Tank Analysis System Mitigation Actions}

The at-tank analysis system on the mobile, variable-depth sampler provides waste measurements from which the mixing and settling status of a tank can be assessed quickly. The variable-depth range of the sampling system provides a waste stream for the at-tank analysis system from any depth within a waste batch. This allows the acquisition of a measurement profile for any size waste batch with the mixer pumps either operating or shut down. 
The waste status data will allow a decision process to be used that identifies a path forward for the waste batch, including the need for mixing, blending, or decanting. The at-tank analysis system data allows management of the waste transfer without the increased costs of the baseline sampling and analysis methods (core or grab sampling with analysis in the 222-S Laboratory).

\section{B3.8 TRANSFERS}

This risk event is identified in 130.E30-1, 130.G30-1, 130.K30-1, 130.K40-1, and 160.U29-1 "Transfers" - Operations Support Risk Management List.

\section{B3.8.1 Risk Statement}

130.E30-1, 130.G30-1, 130.K30-1, 130.K40-1, and 160.U29-1 - Sampling for a tank-to-tank transfer compatibility report may be required if existing sampling data are not acceptable. This sampling activity is not planned and would be underfunded.

\section{B3.8.2 Discussion}

The risk is that WFD schedule and budget impacts will occur if the waste in source tanks must be sampled before transfer between tanks to determine waste compatibility. The schedule and budget for these sampling activities are not planned and would be underfunded. In addition, this unplanned sampling would put an additional burden on the baseline grab and core sampling methods beyond the anticipated WFD and non-WFD work scopes.

\section{B3.8.3 Sampler and At-Tank Analysis System Mitigation Actions}

The mobile, variable-depth sampling system is flexible and can be deployed in any waste tank with an available $30 \mathrm{~cm}$ (12-in.) riser (the design preference is a 15-cm (6-in.) riser). The sampling and at-tank analysis systems are mounted on a skid that is deployed by a crane. The crane requires only a clear area around the riser. All utilities needed during a sampling campaign, including electrical power, compressed air, and flush water, are supplied by an on-board utility system mounted on this skid. This eliminates the need to tap into the utility system of the tank farm, which may not be available or may not have the capacity to support the sampling system. This allows the sampling system to be deployed and removed quickly.

The mobile, variable-depth sampling system can obtain samples of any size waste batch and from any waste depth with its precise control of sampling depth. In addition, each sample bottle filled by the mobile, variable-depth sampling system will meet the RCRA criteria for materials containing volatile and semivolatile organic constituents. The sampler system completes its sampling operations using remote manipulators in sealed chambers with shielding to protect operators from high-dose-rate samples. This will allow the sampling system to be used for any waste batch or partial waste batch that needs to be sampled. 


\section{HNF-2906 REV 1}

\section{B3.9 MIXING}

This risk event is identified in 160.A64-1 and 160.K05-1 - Operations Support Risk Management List.

\section{B3.9.1 Risk Statement}

160.A64-1 and 160.K05-1 - After sampling, the waste would settle enough to require repeated mixer pump operation before the transfer. Additional mixer pump operations would be underfunded.

\section{B3.9.2 Discussion}

The risk is that the waste samples may not be representative of the waste batch because of settling between the time samples were drawn and the time of transfer. The current baseline grab and core sampling methods cannot obtain samples while the mixer pumps are operating. Additional time and cost for this unplanned mixing and need for repeated sampling will lengthen the delivery schedule and increase the cost to prepare a waste batch for transfer.

\section{B3.9.3 Sampler and At-Tank Analysis System Mitigation Actions}

The mobile, variable-depth sampler can obtain samples while the mixer pump is operating. In addition, the at-tank analysis system can provide waste measurements from which the mixing and settling status of a tank can be assessed whether or not the mixer pumps are operating. The variable-depth feature of the sampling system provides a waste stream from any depth within a waste batch and allows the acquisition of a profile of data or samples that is independent of the size of the waste batch.

These data from the at-tank analysis system allow management of the tank's waste status without the increased costs that would be incurred if baseline sampling and analysis methods were used for interim-status measurements.

\section{B3.10 WASTE INTEGRATION TEAM/DOE MAY REQUIRE SAMPLING OF TANKS BEFORE WFD NEEDS THEIR SAMPLE}

This risk event is identified in 130.044-1 - Retrieval Operations Engineering Risk Management List.

\section{B3.10.1 Risk Statement:}

130.044-1 - May accelerate need data for guidance, DQO modifications, and data evaluations. 
HNF-2906 REV 1

\section{B3.10.2 Discussion}

The risk is that the Waste Disposal Integration Team (WDIT) or DOE may require tank sampling before WFD needs samples to validate the waste, as required before transfer to BNFL. This places unplanned and increased demands on the baseline grab or core sampling capabilities. The sampling may need to be repeated depending on the conditions in the tank or if the sampling was completed before the installation of mixer pumps. (Using the mixer pumps will significantly alter the waste batch condition.) The samples from settled sludge areas of the tank may have high radioactive content that would increase dose levels for operators.

\section{B3.10.3 Sampler and At-Tank Analysis System Mitigation Actions}

The mobile, variable-depth sampling system is flexible and can be quickly deployed in any waste tank through a $30 \mathrm{~cm}$ (12-in.) riser (the design preference is a 15-cm [6-in.] riser). The sampling system can rapidly obtain and package $500 \mathrm{~mL}$ sample bottles for transfer using the Steel Pig system. The sampling system is mounted on a skid that also contains all utilities needed during a sampling campaign including electrical power, compressed air, and flush water, which reduces the need to tap into the utility system of the tank farm, which may not be available or may not have the capacity to support the sampling system.

Samples can be obtained from any size waste batch and from any depth in a tank with the precise depth control of the sampling system. Each sample bottle filled by the mobile, variable-depth sampling system will meet the RCRA criteria for materials containing volatile and semivolatile organic constituents. In addition, the design of the sampling system allows it to be redeployed in the same riser at a cost lower than the original deployment because the in-tank hardware can be left in the tank and used in the redeployment. The in-tank hardware will be removed later, when all sampling from that tank is completed. This provides an efficient and economical deployment process based on the experience from the deployment of drill strings using the current core truck system. 


\section{HNF-2906 REV 1}

\section{APPENDIX C}

\section{BUDGETS}

C-i 


\section{HNF-2906 REV 1}

This page intentionally left blank.

C-ii 


\section{APPENDIX C}

\section{BUDGETS}

\section{C1.0 DEVELOPMENT, TEST, AND DEPLOYMENT}

The following cost estimate will provide a prototype sampler system with an at-tank analysis system that is ready for hot deployment to support sampling needs for the privatization contract. Table $\mathrm{C}-1$ shows the cost breakdown by program activity and fiscal year; Table $\mathrm{C}-2$ shows the breakdown of these costs by the EM-30 and EM-50 agency anticipated to be the funding source. The total cost to provide a prototype mobile, variable-depth sampling system with an at-tank analysis system is estimated to be about $\$ 8.8$ million. This cost estimate includes the following:

- Designing, fabricating, and testing basic system concepts

- Completing 30 percent (outline) and 100 percent (detailed) designs

- Fabricating and cold-testing the prototype system

- Integrating the mobile, variable-depth system with the at-tank analysis system and completing cold testing with the integrated system

- Completing a hot-testing campaign with the integrated system in a waste tank

- Training the operators

- Completing formal readiness reviews

- Upgrading the authorization basis

- Pursuing environmental permitting.

\section{C2.0 SYSTEM DUPLICATION COST ESTIMATE}

The estimated cost to produce a duplicate mobile, variable-depth sampler with an at-tank analysis system is $\$ 2.1$ million. Table C-3 shows the breakdown for this cost estimate. 


\section{C3.0 OPERATIONAL SUPPORT COST ESTIMATES}

The cost estimate to complete a sampling campaign in a waste tank is approximately $\$ 300,000$. This includes the following activities:

- System setup and in-tank deployment

- Acquisition of approximately 15 samples over the depth of the waste in the tank

- System removal and disposal of in-tank sampling system components.

The cost for continued use and operation of the system would be comparable to that for the deployment of the core sampling truck system. If the system is left inside a waste tank between sampling campaigns, a cost would be incurred to maintain the system in a standby condition where it is ready to use. The cost for maintaining the system inside a tank in a hot readiness state is estimated to be about $\$ 200,000$ per year. This covers the periodic surveillance and maintenance the system needs. 


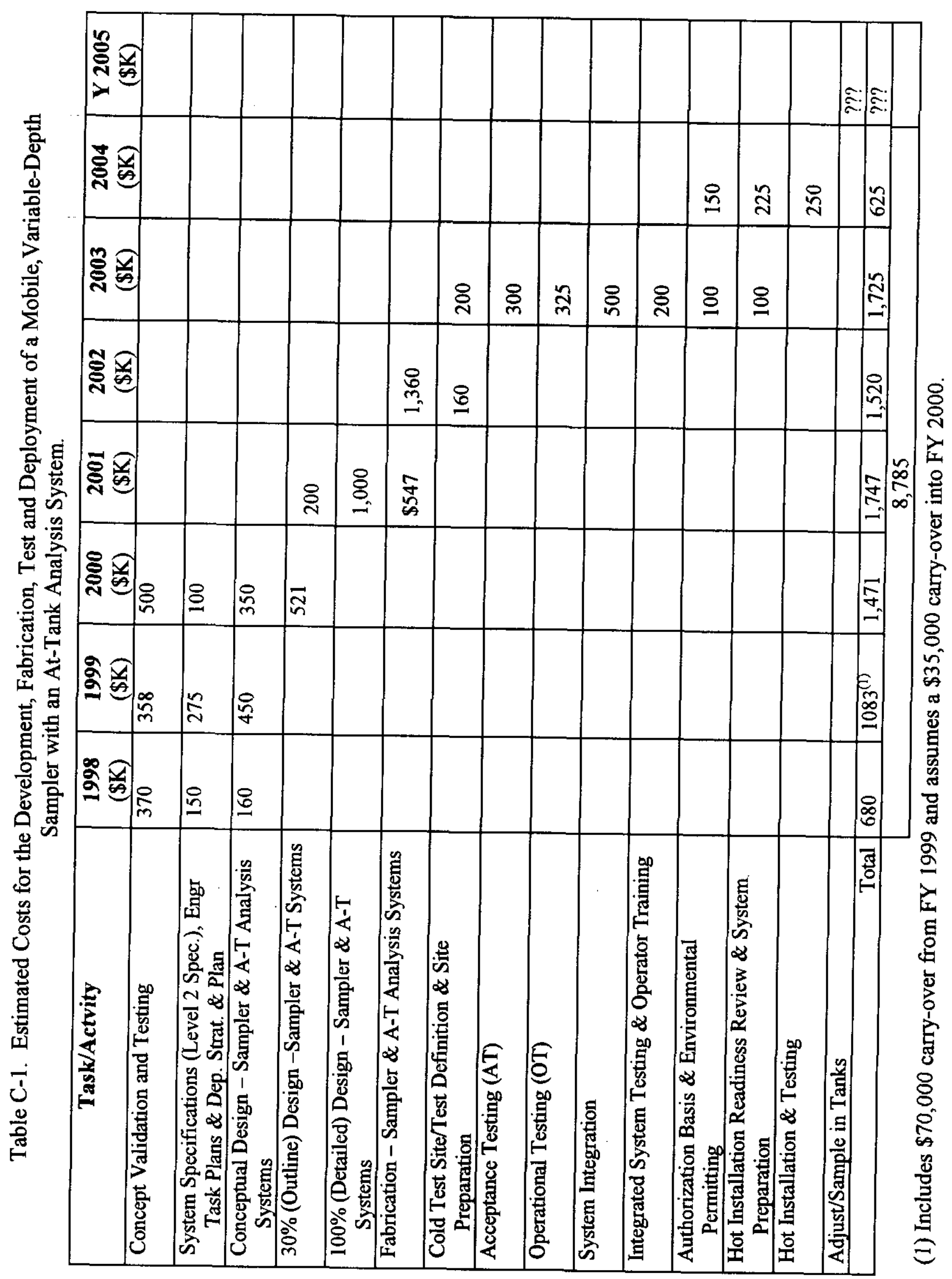


HNF-2906 REV 1

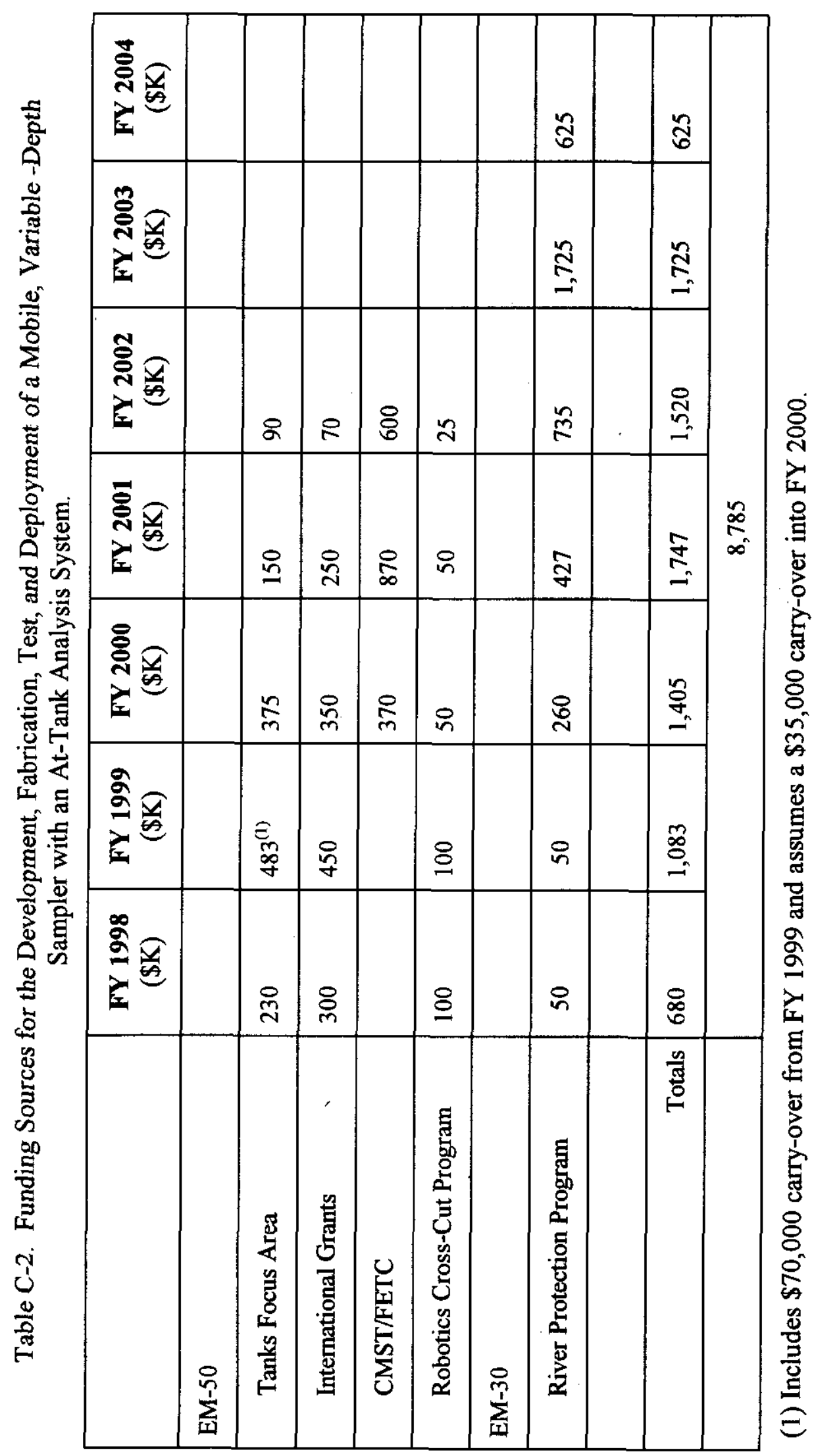


HNF-2906 REV 1

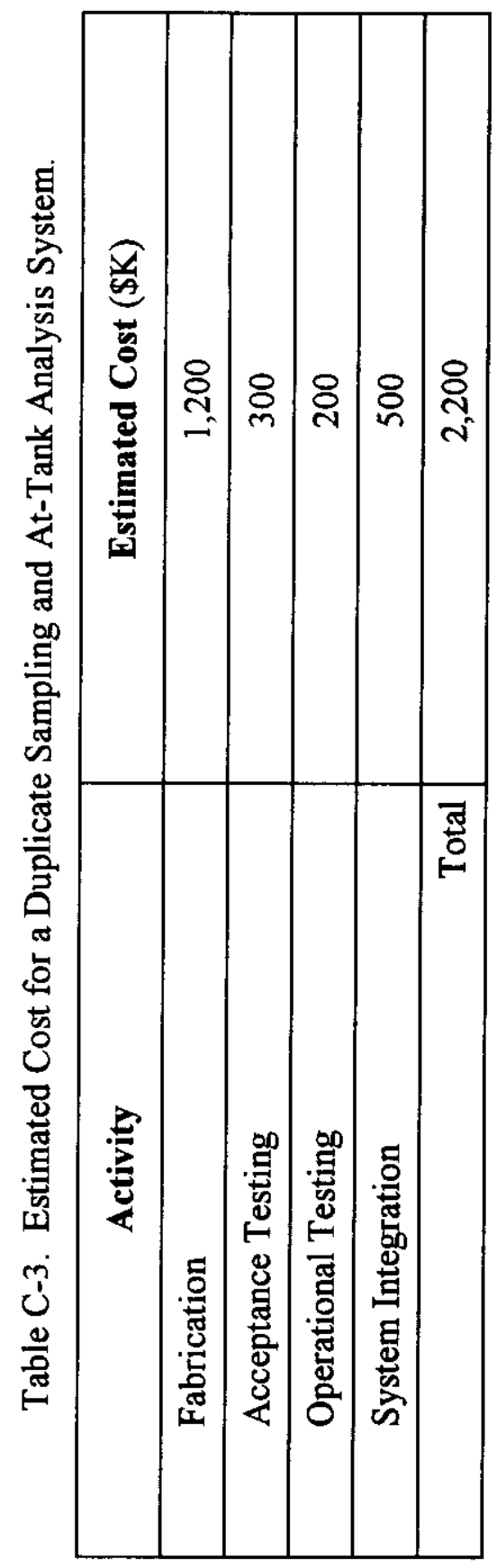

C-5 
HNF-2906 REV 1

\section{APPENDIX D}

\section{SUMMARY OF ALTERNATIVES EVALUATION}

D-i 


\section{HNF-2906 REV 1}

This page intentionally left blank.

D-ii 
HNF-2906 REV 1

APPENDIX D

SUMMARY OF SAMPLER ALTERNATIVES EVALUATION

\section{D1.0 ALTERNATIVES EVALUATION SUMMARY}

Claghorn (1997) considered the following three alternatives:

1. Grab sampler

- Least expensive

- Available at present

- Highest radiation exposure

- Potential for personnel contamination

- Most susceptible to being delayed by weather conditions.

2. Core Sampler

- Expensive

- Available at present

- Susceptible to being delayed by weather conditions.

3. Isolok Sampler

- Expensive initial installation

- Lowest per-feed-batch (recurring) cost

- Will not be ready for full operation by October 1,2000

- Substantially reduces radiation exposure

- Not susceptible to being delayed by weather conditions. 


\section{HNF-2906 REV 1}

\section{D2.0 REFERENCES}

Claghorn, R. D., J. D. Galbraith, and T. B. Salzano, 1997, Alternatives Generation and Analysis for the Phase I Intermediate Waste Feed Staging System Design Requirements, HNF-SD-TWR-AGA-001, Rev. 1, prepared by Numatec Hanford Corporation for Fluor Daniel Hanford, Inc., Richland, Washington.

Jordan, K. N., 1998, Tank Waste Remediation System Retrieval and Disposal Mission Readiness-to-Proceed Memorandum, HNF-2019, Rev. 1, Fluor Daniel Hanford, Inc., Richland, Washington. 


\section{DISTRIBUTION}

Number of Copies $\quad \underline{\text { Address }}$

\section{OFFSITE:}

(2)

U.S. Department of Energy

Office of Technology Systems

19901 Germantown Road

Cloverleaf Building, room 1154

Germantown, MD 20874-1290

K. D. Gerdes

(2)

AEA Technology Engineering Services, Inc. 13245 Reese Boulevard West, Suite 100

Campbell Building

Huntersville, NC 28078

Paul Murray

Martin Williams

(1)

Ames Laboratory 125 Spedding Hall

Iowa State University

Ames, IA 50011

G. J. Bastiaans

(2)

Bechtel Babcock and Wilcox Idaho (BB\&W)

P. O. Box 1625

Idaho Falls, ID 83415-3760

T. R. Thomas

B. H. O'Brien

(2)

U.S. Department of Energy - National Energy

Technology Laboratory

3610 Collins Ferry Road

Morgantown, WV 26507-0880

R. K. Staubly

W.F. Haslebacher 


\section{DISTRIBUTION}

Number of Copies

OFFSITE:

(1)

(1)

(1) $\underline{\text { Address }}$

Oak Ridge National Laboratory

P. O. Box 2008

Oak Ridge, TN 37831-6044

Dr. Sharon M. Robinson

Pacific Rim Enterprise Center

660 George Washington Way

Richland, WA 99352

V. Panesko

Westinghouse Savannah River Corporation

Savannah River Technology Center,

$703 \mathrm{H}$ Bldg.

Aiken, SC 29808

J. P. Morin 


\section{DISTRIBUTION}

Number of Copies
ONSITE

(7)

U.S. Department of Energy, Richland

Operations Office

E.J. Cruz (2) H6-60

R. Carreon H6-60

W. Liou H6-60

J. A. Poppiti H6-60

J. F. Thompson, Jr. H6-60

N.C. Welliver H6-60

(1) DOE Public Reading Room J2-53

$\begin{array}{lll}\text { (2) Central Files } & \text { B1-07 }\end{array}$

(1) DE\&S Hanford. Inc. $\quad$ R1-49

T.G. Goetz 
HNF-2906 REV 1

\section{DISTRIBUTION}

Number of Copies

ONSITE

(22)

(1)

\section{CH2M Hill Hanford Group. Inc.}

J. N. Appel

H6-64

J. H. Baldwin

R3-73

R. G. Brown

S7-12

T. W. Crawford

R3-73

K. A. Gasper(3)

M. D. Hasty

H6-64

J. G. Field

S7-01

H6-62

J. O. Honeyman

H6-62

H. R. Hopkins II

R2-58

C. D. Jackson

S7-34

G. P. Janicek

S7-12

M. L. McElroy

S7-07

L. L. Penn

S7-03

R. S. Popielarczyk

R2-58

J. S. Schofield

S7-12

J. F. Sickels

S7-03

G. A. Stanton, Jr.

A. M. Templeton

J. A. Voogd

D. J. Washenfelder

S7-01

R2-12

H6-64

H6-62

MAC Technical Services Corporation

R. L. Treat

H6-64 
HNF-2906 REV 1

\section{DISTRIBUTION}

Number of Copies $\quad$ Address

\section{ONSITE}

(4)

Numatic Hanford Corporation

R. M. Boger S7-12

J. S. Garfield R3-72

M. J. Schliebe L6-13

J. P. Sloughter $\quad$ K9-46

(5)

Pacific Northwest National Laboratory

S. A. Bailey K5-08

B. A. Carteret K9-91

R. L. Gilchrist K9-91

M. W. Rinker K5-22

K. D. Wiemers H6-61

(1) Hanford Technical Library P8-55

(4) COGEMA-Engineering Corporation

J. L. Smalley

F. R. Reich (2)

S7-12

H1-19

G. W. Wilson

S7-12 


\section{HNF-2906 REV 1}

This page intentionally left blank.

Dist-6 


\section{DISTRIBUTION}

Number of Copies

OFFSITE:

(2)

(2)

(1)

(2)

(2)
U.S. Department of Energy

Office of Technology Systems

19901 Germantown Road

Cloverleaf Building, room 1154

Germantown, MD 20874-1290

K. D. Gerdes

AEA Technology Engineering Services, Inc. 13245 Reese Boulevard West, Suite 100

Campbell Building

Huntersville, NC 28078

Paul Murray

Martin Williams

Ames Laboratory

125 Spedding Hall

lowa State University

Ames, IA 50011

G. J. Bastiaans

Bechtel Babcock and Wilcox Idaho (BB\&W)

P. O. Box 1625

Idaho Falls, ID 83415-3760

T. R. Thomas

B. H. O'Brien

U.S. Department of Energy - National Energy

Technology Laboratory

3610 Collins Ferry Road

Morgantown, WV 26507-0880

R. K. Staubly

W.F. Haslebacher 
HNF-2906 REV 1

\section{DISTRIBUTION}

Number of Copies $\underline{\text { Address }}$

OFFSITE:

(1)

Oak Ridge National Laboratory

P. O. Box 2008

Oak Ridge, TN 37831-6044

Dr. Sharon M. Robinson

(1)

Pacific Rim Enterprise Center 660 George Washington Way

Richland, WA 99352

V. Panesko

(1).

Westinghouse Savannah River Corporation Savannah River Technology Center, $703 \mathrm{H}$ Bldg.

Aiken, SC 29808

J. P. Morin

Dist-2 


\section{DISTRIBUTION}

Number of Copies $\quad$ Address

\section{QNSITE}

(7)

U.S. Department of Energy, Richland Operations Office

E.J. Cruz (2) H6-60

R. Carreon H6-60

W. Liou H6-60

J. A. Poppiti H6-60

J. F. Thompson, Jr. H6-60

N.C. Welliver H6-60

(1) DOE Public Reading Room J2-53

$\begin{array}{ll}\text { (2) Central Files } & \text { B1-07 }\end{array}$

(1) DE\&S Hanford. Inc. R1-49

T.G. Goetz 
HNF-2906 REV 1

\section{DISTRIBUTION}

Number of Copies $\quad \underline{\text { Address }}$

\section{ONSITE}

(22)

\section{CH2M Hill Hanford Group, Inc.}

J. N. Appel

H6-64

J. H. Baldwin

R3-73

R. G. Brown

S7-12

T. W. Crawford

R3-73

K. A. Gasper(3)

$\mathrm{H} 6-64$

M. D. Hasty

S7-01

J. G. Field

$\mathrm{H} 6-62$

J. O. Honeyman

H6-62

H. R. Hopkins II

R2-58

C. D. Jackson

S7-34

G. P. Janicek

S7-12

M. L. McElroy

S7-07

L. L. Penn

S7-03

R. S. Popielarczyk

R2-58

J. S. Schofield

S7-12

J. F. Sickels

S7-03

G. A. Stanton, Jr.

S7-01

A. M. Templeton

R2-12

J. A. Voogd

H6-64

D. J. Washenfelder

H6-62

(1)

MAC Technical Services Corporation

R. L. Treat

H6-64 
HNF-2906 REV l

\section{DISTRIBUTION}

Number of Copies Address

\section{ONSITE}

(4)

Numatic Hanford Corporation

R. M. Boger S7-12

J. S. Garfield R3-72

M. J. Schliebe L6-13

J. P. Sloughter K9-46

(5)

Pacific Northwest National Laboratory

S. A. Bailey K5-08

B. A. Carteret K9-91

R. L. Gilchrist K9-91

M. W. Rinker K5-22

K. D. Wiemers H6-61

(1) Hanford Technical Library P8-55

(4) COGEMA-Engineering Corporation
J. L. Smalley
S7-12
F. R. Reich (2)
$\mathrm{H} 1-19$
G. W. Wilson
S7-12 